\title{
Performance analysis of a rotating detonation combustor based on stagnation pressure measurements
}

Eric Bach ${ }^{\mathrm{a}, *}$, Panagiotis Stathopoulos ${ }^{\mathrm{b}}$, Christian Oliver Paschereit ${ }^{\mathrm{a}}$, Myles

\author{
D. Bohon ${ }^{\mathrm{a}}$ \\ ${ }^{a}$ Chair of Fluid Dynamics \\ Technische Universität Berlin \\ 10623 Berlin, Germany \\ ${ }^{b}$ Chair of Unsteady Thermodynamics in Gas Turbine Processes \\ Technische Universität Berlin \\ 10623 Berlin, Germany
}

\begin{abstract}
This study explores the effect of differing inlet and outlet boundary conditions on the operation and performance of a rotating detonation combustor (RDC) over an annulus mass flux range of 50 to $210 \mathrm{~kg} \cdot \mathrm{s}^{-1} \cdot \mathrm{m}^{-2}$ and equivalence ratios of $0.7,1.0$, and 1.3 . The RDC is equipped with either a uniform outlet restriction or with a set of nozzle guide vanes to simulate turbine integration. Stagnation pressure data from Kiel probes placed in the high-enthalpy exhaust flow are presented for the operational envelope. The RDC's operation is categorized into different modes distinguished by the number of co- and counter-rotating combustion waves in the annulus. With increasing mass flux, a typical progression proceeding from a pair of counterrotating waves, to a single detonation wave, and then further to multiple co-rotating waves is observed with wave speeds reaching up to $84 \%$ of the
\end{abstract}

\footnotetext{
${ }^{*}$ Corresponding Author

Email address: eric.bach@tu-berlin.de (Eric Bach)
} 
CJ velocity. It is shown that a choking condition at the outlet throat correlates with the transition from two counter-rotating waves to a single wave detonation regime. The channel Mach number is then calculated from measured pressure ratios and is shown to agree with area ratio-based estimates. The pressure gain of the RDC is expressed as the stagnation pressure change from the air plenum to the outlet throat, and it is shown that the specific operating mode of the device - in conjunction with the chosen injector and outlet area ratios - can significantly decrease the pressure gain performance in some cases, while not significantly affecting it in others. While no positive pressure gain was achieved in the experiments, the presented experimental data compare well with numerical results of similar boundary conditions and underline the importance of minimizing injector pressure loss while applying outlet restrictions to the combustor. The data also suggest that specific geometric combinations may lead to adverse modes such as longitudinally pulsing combustion, resulting in a reduction in the measured pressure gain relative to numerical results. This observation occurs more often for geometric combinations which are the most promising for exhibiting positive pressure gain, and suppressing these modes will be an important topic to achieving this goal. It is further shown that transition regions exist between modes of one and multiple co-rotating waves, and that wave multiplication may be necessary to unlock further increases in the pressure gain.

Keywords: rotating detonation engine, pressure gain combustion, stagnation pressure, injector design 


\section{Nomenclature}

$\begin{array}{ll}A & \text { area }\left(\mathrm{mm}^{2}\right) \\ \gamma & \text { ratio of specific heats }(-) \\ D & \text { outer diameter }(\mathrm{mm}) \\ d & \text { inner diameter }(\mathrm{mm}) \\ f & \text { frequency }(\mathrm{Hz}) \\ J & \text { mass flux }\left(\mathrm{kg} \cdot \mathrm{s}^{-1} \cdot \mathrm{m}^{-2}\right) \\ L & \text { length }(\mathrm{mm}) \\ \mathrm{M} & \text { Mach number }(-) \\ p & \text { pressure }(\text { bar }) \\ \phi & \text { equivalence ratio }(-) \\ t & \text { time }(\mathrm{s}) \\ v & \text { velocity }\left(\mathrm{m} \cdot \mathrm{s}^{-1}\right) \\ z & \text { axial coordinate }(\mathrm{mm})\end{array}$




$$
\begin{array}{cl}
\text { Subscripts } \\
\text { a } & \text { axial } \\
\text { c } & \text { combustion annulus } \\
\text { ch } & \text { choked flow } \\
\text { CJ } & \text { Chapman-Jouguet } \\
\mathrm{i} & \text { injector } \\
\mathrm{k} & \text { kinetic } \\
\mathrm{r} & \text { outlet restriction } \\
\mathrm{s} & \text { static } \\
\mathrm{t} & \text { stagnation } \\
\mathrm{w} & \text { wave } \\
0 & \text { value at } t=0
\end{array}
$$

\section{Introduction}

Pressure Gain Combustion (PGC), through the use of a detonative combustion process, has great potential to be a disruptive technology for both propulsion and power generation (as described by Stathopoulos [1]). It promises to increase system efficiency and lower fuel consumption, unlocking a step change in the performance of land-based and aviation gas turbine engines as well as rocket motors. In a Rotating Detonation Combustor (RDC), a detonation wave propagates around an annulus, in which fresh reactants are continuously introduced [2]. The frequency of the detonation wave passage is in the $\mathrm{kHz}$ range, resulting in a quasi-steady, high-enthalpy exhaust flow. In order to reap the benefits of this technology, research is being directed toward the integration of RDCs into gas turbine engines [3-6]. However, in pursuit of this goal, a number of challenges arise due to the inherently unsteady and 
highly fluctuating detonation phenomenon $[7,8]$. The instationary exhaust flow can vary between transonic and supersonic conditions [9] and exhibit high-frequency pressure fluctuations [8], resulting in additional mechanical stresses for hot gas path components. Increased power density puts high demands on thermal management, while the products of the detonation process constitute a harsh environment for instrumentation. Further complexities in the form of patterning and velocity fluctuations in the exhaust flow are challenging for state-of-the-art components [10]. It is therefore desirable to obtain better information about the exhaust flow in order to quantify the requirements of subsequent components, as well as to assess the RDC's performance at various operating and boundary conditions.

Paxson and Kaemming [9,11-13] have examined the topic of pressure gain and how it may be quantified for different devices and configurations. In [11], the authors propose an averaging technique that allows for a comparison between deflagration- and detonation-based gas turbine engines. The impact of a PGC device's inherent unsteadiness is addressed in [12], which provides a consistent means of mass, momentum and energy conservation in order to compare unsteady and steady cycle performance. A 2-D CFD simulation was later conducted in [13], specifically exploring the impact of an outlet restriction on RDC performance. Reducing the inlet Mach number in this way was demonstrated to result in an increase of specific impulse of around 9.5\%. A too severe restriction, however, led to detonation failing. The same study also showed that a non-aerodynamic injector can add stability and improve specific impulse due to reduced fill Mach number and improved mixing. Recently in [9], a common framework for comparing PGC devices 
used for work extraction or to produce thrust is presented. While based on a set of 2-D CFD simulations, the approach chosen by the authors was designed to also be transferable to experimental data. The presented formulation was tested on different configurations of an RDC, evaluating the effect of injector and outlet area ratio variation. Among several other effects, it was shown that a net pressure gain is most probable for devices with increased injector area ratio and an outlet restriction.

A meaningful characterization of RDC performance is therefore linked to imposing appropriate boundary conditions. Several studies have investigated RDCs coupled to differently shaped nozzles, either to introduce back pressure or generate thrust. An overview is given by Anand and Gutmark [14]. Because of the RDC's annular design, plug or aerospike nozzles [15] are a natural match for generating thrust. At the Air Force Research Lab (AFRL), Fotia et al. $[16,17]$ studied the propulsive performance of various nozzle designs. While they detected a significant increase of static pressure in the combustor, the measured thrust was less than predicted due to "the propagation of shock waves through the exhaust gases". They further stipulate thrust production dependence on the nozzle internal expansion ratio and propose a thrust coefficient for airbreathing RDCs based on the area and stagnation pressure at the air injector. Meanwhile, aerospike truncation was not observed to affect the operating mode. A similar RDC experiment at the AFRL with a conical centerbody and a converging-diverging nozzle was examined by Paxson et al. [18] and Rankin et al. [19]. It was shown that the nozzle reduced the periodic nature of the flow and that CFD simulations were able to reproduce the measured static pressure distribution. 
Stechmann et al. describe a nozzle design dependent performance model $[20,21]$. They emphasize the importance of finding an appropriate contour and the fact that mean pressure is not a befitting metric as the RDC benefits greatly from the above-average impulse in each cycle. Thrust measurements were conducted to quantify performance, but it was mentioned that chamber pressure metrics, albeit challenging to obtain, could be used instead.

Frolov et al. [22] introduced a large-scale experiment in Russia, comprising an RDC with an aerospike nozzle and an optional triangular throat that blocks off $50 \%$ of the annulus area. They observed a direct correlation between injector area, restriction of the flow path, the number of co-rotating detonation waves and the thrust produced by the device. Decreasing the fill Mach number by way of adding an outlet restriction or increasing the injector area increases the number of detonation waves. However, axially pulsing combustion was also observed for a very large air injector area and high outlet restriction. Adding an outlet restriction and an aerospike nozzle both led to improved thrust (by a factor of 2) compared to variants with unobstructed outlet and/or no nozzle.

In Japan, an RDC was equipped with a conical plug nozzle of different area restriction ratios for rocket propulsion, as described by Nishimura et al. [23] and Goto et al. [24]. They report that combustor static pressure was proportional to throat mass flux and recorded specific impulse at $84 \%$ of the ideal value, which they speculate to be due to a mismatch of nozzle operating conditions or the varying propellant combinations $\left(\mathrm{CH}_{4}\right.$ and $\mathrm{C}_{2} \mathrm{H}_{4}$ were used).

Apart from adding a nozzle to the combustor, several studies have also 
focused on the integration of an RDC into a nozzle guide vane (NGV) proxy or an actual gas turbine. At the AFRL, Tellefsen [25] examined both a convergent nozzle and a JetCat P-200 turbine placed downstream of an RDC. He found that significant pressure fluctuations persisted throughout the singlestage radial-flow turbine. He also determined that the RDC operates similarly for both nozzle and turbine testing, and that wave speed is mainly influenced by back pressure. DeBarmore [26] describes a setup with an axial flow T63 turbine behind an RDC. Stagnation pressures (with a Kiel probe) and static temperatures (with thermocouples) were measured before and after the first stage nozzle guide vanes. They found that for their configuration, flow unsteadiness decreased by $60 \%$ on average over the guide vane row, and were able to quantify the RDC exhaust temperature to around $1000^{\circ} \mathrm{C}$ at a location approximately $250 \mathrm{~mm}$ downstream of the detonation front when at lean equivalence ratios $(\phi=0.41)$. Naples et al. $[27,28]$ used the same setup to measure stagnation pressure with Kiel shrouds integrated into the vane stages and pressure unsteadiness up- and downstream of the turbine. In their experiment, the RDC exhaust flow was diluted with air to lower the turbine inlet temperature. They found that initial RDC unsteadiness reached 25\%, but was significantly attenuated through the first two turbine stages. Furthermore, they found radial temperature variations in both turbine stages for $\mathrm{RDC}$ operation, indicating an uneven temperature distribution in the outlet of the combustor.

A similar experiment with an RDC integrated into a GTD-350 helicopter gas turbine at Warsaw's Institute of Aviation is described by Wolanski [3] and Kalina et al. [29]. The approach was similar to the AFRL experiment, 
and the main focus of the experiment was to compare power and fuel consumption characteristics between deflagration and detonation combustion. With the RDC combustor, an improvement between 5 and $7 \%$ in fuel burn was achieved. As only a limited amount of data were published, it is difficult to identify the specific impact of the detonation process on the flow characteristics.

Higashi et al. [30] and Rhee et al. [31] describe two experiments conducted at Nagoya University. Higashi et al. coupled a centrifugal compressor, a radial-outward combustor and a radial turbine on one side of a rotor disk. However, the observed wave speed only attains $25-45 \%$ of CJ velocity and flow separation occurred in the turbine, rendering the effort unsuccessful. Rhee et al. on the other hand looked at a closed-loop gas turbine equipped with an RDC. They show successful operation of the turbine, a turbine inlet temperature of about $3000 \mathrm{~K}$, and a wave speed of $91.6 \%$ CJ velocity, however only a limited subset of data are presented and it is difficult to interpret the specific features of this system.

The AFRL designed a further experiment with a radial RDC coupled to an integrated automotive turbocharger, as presented by Huff et al. [32, 33]. The experiment measured the power output of the turbine over a wide mass flow and RPM range. Using a variety of instrumentation, including a Kiel probe and thermocouples downstream of the turbine, a maximum efficiency of $40 \%$ was recorded with this setup. The compressor and turbine pressure ratios were varied by adjusting their respective back pressures, resulting in additional power output in the case of compressor pressurization and lower power output for a pressurized turbine. These results are thought to be rep- 
resentative of a realistic configuration where an RDC might drive a turbine with nozzled outlet flow, such as in an APU. The authors further discriminate between detonation operation and acoustically driven combustion, with an increase in efficiency for detonation operation. No explanation for the occurrence of the two modes is given, but the results suggest that below and above certain mass flux values, acoustically driven combustion is established. One key feature of the experiment is a set of NGVs between RDC and turbine, which were manufactured for different turning angles of $23.5^{\circ}, 32^{\circ}$, and $39^{\circ}$. While no information is given about the specific shape of the NGVs, the flow turning angle had a profound impact on the measured specific power. For an optimal design, vane angle and mass flow would need to be adjusted independently.

A research group at China's Nanjing University coupled an RDC to an unspecified guide vane stage, turning the flow by $30^{\circ}$ and mimicking turbine operation in an experiment described by Zhou et al. [34, 35]. An increase of wave speed of about $4 \%$ was observed with guide vanes in the flow path compared to an unobstructed outlet, as well as an attenuation of pressure oscillations by $64 \%$ when passing through the vane stage. For guide vane operation, a low frequency instability was observed at $400 \mathrm{~Hz}$. This was not present without the vanes, where the RDC exhibited a two-wave collision mode only.

Numerical and analytical work on appropriate turbine design for integration with an RDC was carried out at Purdue University and the von Karman Institute by Paniagua et al. [36], Braun et al. [7], and Liu et al. [8]. In [36], design guidelines are presented for supersonic axial turbines coupled to RDCs 
and validated with performance studies using CFD. As an intense normal shock is expected to occur at the vane's leading edge, the ability to ingest this shock becomes paramount for vane and blade design. This results in slim profiles with less flow turning compared to subsonic designs. One prime loss mechanism are leading edge shock reflections across the turbine passage. This work was extended in [7], which described the unsteady performance of several transition nozzles downstream of an RDC with CFD simulations. The authors balance a set of optimization parameters such as mean flow angle, total pressure loss, Mach number, and viscous losses, but cannot define one nozzle design suitable for the whole operational range. A conical nozzle shape is more efficient for lower inlet pressure, while a Bezier outer wall nozzle performs better at high inlet pressure. In [8], both previously described supersonic turbine and exit nozzle are coupled in a 3-D URANS simulation. The importance of a well-designed nozzle is underlined as the turbine suffers from strong oblique shock amplitudes. While the turbine was able to operate at an inlet Mach number of 2, strong unsteadiness at the inlet increases aerodynamic losses.

Stagnation pressure measurements downstream of an RDC were carried out by Aerojet Rocketdyne. Several RDC experiments of different sizes equipped with nozzles are reported by Sonwane et al. [37] and Lynch et al. [38]. The test facility was equipped with a cooled Cobra-type probe to obtain time-resolved angle-of-attack and total pressure data. However, no publicly available summary exists of their findings. No other attempts at measuring total pressure in the undiluted RDC exhaust flow are known to the authors. 
Reliable information of exhaust flow parameters over the operational envelope of an RDC is, however, paramount for understanding the impact on performance of the imposed boundary conditions as well as for new turbine designs or retrofit endeavors. This work sets out the objective to first characterize the operation of an RDC in terms of the speed and the number of co- and counter-rotating combustion waves. This is further complemented with stagnation pressure data from Kiel probes inserted directly into the high-enthalpy exhaust flow. The combination of these information allows to interlink a description of the flow field, inlet and outlet boundary conditions, and stagnation pressure rise to quantify and compare the performance of different configurations. Finally, the experimentally obtained results are contrasted with those from numerical studies.

\section{Experimental setup}

The following section contains an overview of the experimental apparatus, the studied operating range, applied instrumentation, and basic data manipulation schemes.

\subsection{Rotating detonation combustor}

The data presented in this study were gathered using TU Berlin's modular generic rotating detonation combustor [39], which is shown in Figure 1. This device features an annular combustion chamber with an outer diameter, $D$, of $90 \mathrm{~mm}$ and an exchangeable centerbody defining the combustor annulus gap width, $\Delta$. For the present study, only one centerbody $(d=74.8 \mathrm{~mm})$ was employed and the gap width thereby fixed to $7.6 \mathrm{~mm}$. This results in a combustion annulus area of $A_{\mathrm{c}}=1967.4 \mathrm{~mm}^{2}$. The length $L_{\mathrm{s}}$ of the 

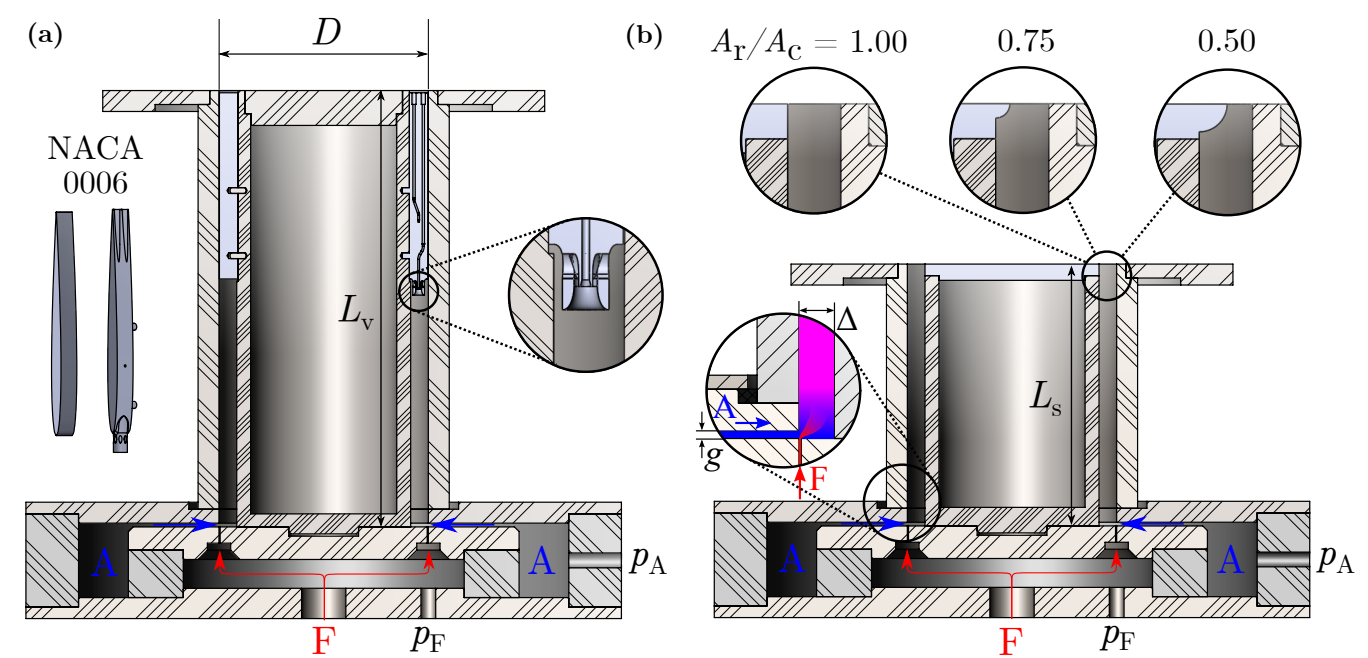

Figure 1: Cross-sections of modular RDC setup, with oxidizer and fuel flow paths highlighted in blue and red. (a) Guide vane setup with detail view of leading edge Kiel head and vane profile, (b) uniform outlet setup with detail views of fuel injection and mixing scheme and different outlet restriction plates. Indicated are the general characteristics of the RDC: Diameter $D$, length $L$, gap width $\Delta$, air injector gap height $g$, reactant plena (A - air, F - fuel) and pressure taps $p$, as well as the outlet throat to combustor area ratio $A_{\mathrm{r}} / A_{\mathrm{c}}$ for the uniform outlet variants. 
combustor is $110 \mathrm{~mm}$. All data were obtained with hydrogen as fuel and air as oxidizer, with the air being introduced radially-inward through a narrow gap at the bottom of the chamber. Two air injector configurations - a $1 \mathrm{~mm}$ and a $1.6 \mathrm{~mm}$ slot height, $g$ - were investigated. The resulting ratios of injector area to combustion annulus area - a value which is used throughout this manuscript to designate the injector variant - are $A_{\mathrm{i}} / A_{\mathrm{c}}=0.14$ and 0.23 , respectively. The air injector specifications are also summarized in Table 1 in the Appendix. Fuel is introduced into the combustor through an exchangeable fuel plate. The fuel plate for the present study featured 100 evenly spaced injection holes, each measuring $0.5 \mathrm{~mm}$ in diameter, located along the perimeter of the outer wall of the combustor. The fuel injector specifications are also summarized in Table 2 in the Appendix. The fuel jets issuing from these injectors are aligned tangentially to the outer wall and perpendicular to the air stream, which they penetrate in a jet in cross flow arrangement [40]. Reactant plena pressures can be varied individually, up to approximately 12 bar and 25 bar for the air and fuel injection, respectively. Both reactant flows are metered with sonic nozzles upstream of the respective plena, and are supplied at ambient temperature $(T \approx 293 \mathrm{~K})$. An air flow rate range from $0.1 \mathrm{up}$ to $0.4 \mathrm{~kg} \cdot \mathrm{s}^{-1}$ was investigated, with increments of $0.05 \mathrm{~kg} \cdot \mathrm{s}^{-1}$. For each mass flow rate, three different equivalence ratios are considered for lean $(\phi=0.7)$, stoichiometric $(\phi=1.0)$, and rich mixtures $(\phi=1.3)$. A spark plug or pre-detonator tube operating on hydrogen and air ignites the combustion process. No difference in operation was observed between the two ignition sources at the conditions studied here. The ignition source was located on the outer wall, approximately $25 \mathrm{~mm}$ downstream from 
the fuel plate. Prior to ignition, settling times of $3 \mathrm{~s}$ for the air flow and $1 \mathrm{~s}$ for the fuel flow were allowed in order to establish a steady flow field. The reactant feed lines are pressurized prior to the experiment to ensure only minute adjustments are necessary to reach the desired flow rate. Domeloaded pressure regulators with a time constant that is small compared to the settling time are then used to control the feed line pressure while both reactants are flowing. The settling times are chosen so that the mass flow is stationary at the time of ignition. An example of the flow rate steadiness over the course of one run is given in Fig. 12 in the Appendix.

\subsection{Outlet restriction configurations}

In order to introduce a generic area restriction and thereby impose back pressure on the combustion chamber, different variants of the centerbody end plate were produced. A detailed view of these plates is shown in Fig. 1b. One variant allows an unobstructed exit, while two other versions incorporate a uniform, quarter-round area contraction. These extend $2.04 \mathrm{~mm}$ and $3.98 \mathrm{~mm}$ into the annulus, respectively, resulting in a blockage of 25 and $50 \%$ of the area at the exit. In this manuscript, the throat area is referred to as $A_{\mathrm{r}}$. A top-down view comparing the three variants is displayed in Fig. 2a.

In addition to the uniform outlet restrictions, a second configuration containing a set of guide vanes aligned in the streamwise direction is incorporated. A depiction of this setup is given in Fig. 1a. The number of installed vanes can be changed, and for this study, three different configurations were considered with 6,9, and 18 vanes. A top-down view comparing the three variants is displayed in Fig. 2b. Following design guidelines given by Paniagua et al. [36], a symmetrical, generic profile suitable for transonic flows 

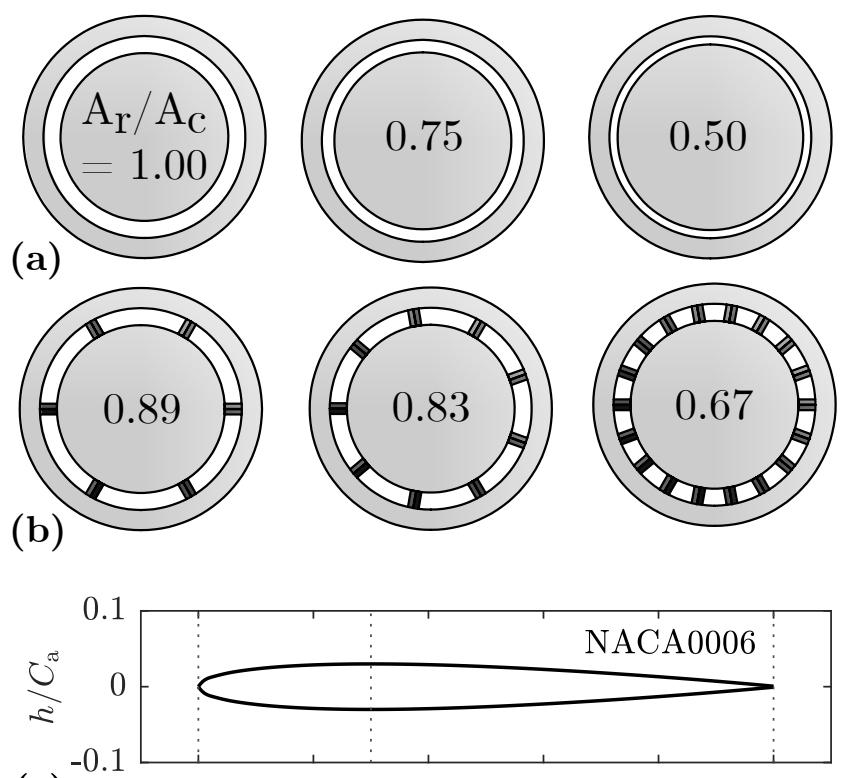

(c)

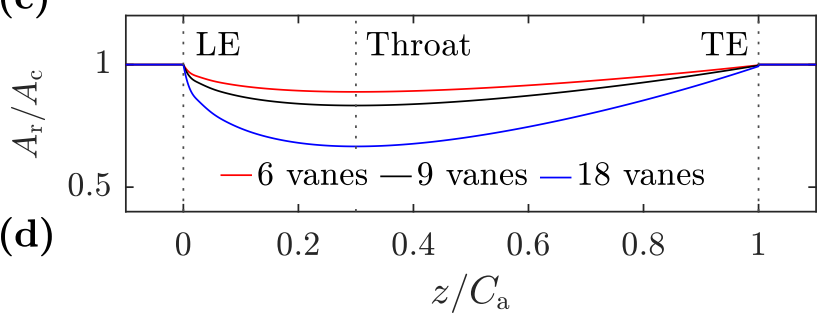

Figure 2: Characterization of different RDC restrictions. (a) Top-down view of uniform outlets, (b) top-down view of guide vane setup with number of installed vanes increasing from left to right, (c) schematic of vane profile, and (d) area blockage along the flow path of vane section. Indicated are the restriction throat to combustor annulus area ratios $A_{\mathrm{r}} / A_{\mathrm{c}}$ for each configuration. 
was chosen for the vanes: the NACA0006 airfoil described, e.g., by Jacobs et al. [41]. The total axial chord length, $C_{\mathrm{a}}$, of the vanes is $80 \mathrm{~mm}$ and the maximum thickness, $h$, of a single vane at the throat is $4.8 \mathrm{~mm}$ (or $0.06 C_{\mathrm{a}}$ ). The throat is located at $0.3 C_{\mathrm{a}}$ and corresponds to a maximum area restriction of $11.1,16.7$, and $33.4 \%$, respectively (see Fig. 2c\&d for a schematic). The overall length of the combustor was extended to $L_{\mathrm{v}}=190 \mathrm{~mm}$ to maintain the total combustion chamber length before the restriction. Downstream of the trailing edge the combustion products are discharged into the lab exhaust.

\subsection{Instrumentation}

Multiple ports in the reactant plena, around, and along the combustion chamber are available for probe placement. Air and hydrogen static feed pressure were obtained with flush-mounted Omega PXM319 transducers in the plena (see $p_{\mathrm{A}}$ and $p_{\mathrm{F}}$ designations in Fig. 1). Values of the average static pressure were taken with capillary tube attenuated pressure (CTAP) probes, for which a detailed description is provided by Fotia et al. [42]. Kulite XTEL190 piezoresistive pressure transducers were installed in the CTAP probes, providing an absolute pressure measurement capability. The standoff length was $200 \mathrm{~mm}$ and the inner diameter of the capillary tube was $2 \mathrm{~mm}$. In both combustor configurations, a total of four axially evenly spaced ports exist upstream of the restriction for instrumentation. Three additional ports are available in the guide vane section. The varying static pressure at the chamber wall was measured using PCB112A05 piezoelectric pressure transducers, placed in a recessed cavity in order to shield them from direct exposure to the detonation process. These holders were designed to exhibit a Helmholtz resonance at a frequency significantly larger than that of the combustion 
process, so as to not interfere with the measurement. A set of at least three sensors distributed circumferentially at an axial distance of about $25 \mathrm{~mm}$ from the fuel injection plate was used for all tests. The circumferential distribution with a spacing of $20^{\circ}$ and $33.3^{\circ}$ between adjacent sensors allows a description of the propagation of detonation and shock waves in the chamber. In most tests, further PCB sensors were placed in the axial direction to identify longitudinally propagating waves as well as to obtain a measure of the attenuation of pressure fluctuations.

In order to obtain stagnation pressure data in the high-enthalpy exhaust flow, an L-shaped Kiel probe [43] was designed and placed just upstream of the RDC outlet. The measurement principle is similar to a Pitot probe (see Chue [44]), however the shrouded probe's inlet is shaped in such a way that the angle of the incident flow can vary without distorting the measurement. The probe chosen here is a proprietary design of Vectoflow $\mathrm{GmbH}$, and the manufacturer allows for an inflow angle variation of $\pm 60^{\circ}$ and up to a Mach number of 2. For comparison, Depperschmidt et al. [45] experimentally observed flow tilt angles just downstream of the exit of an RDC to vary between $\pm 10^{\circ}$, while in a numerical study Schwer et al. [46] report flow angles close to the outlet throat (but still within the chamber) of $-50^{\circ}$ to $23^{\circ}$. Through a capillary tube similar to the one used in the CTAP probes, but with a standoff length of only $100 \mathrm{~mm}$, a Kulite XTEL190 pressure transducer is attached to the Kiel probe. This allows the measurement of average stagnation pressure. The probe was made from a cobalt-chromium high temperature alloy in order to provide sufficient component lifetime.

For the elongated combustor, instrumented guide vanes were designed and 
manufactured from the same alloy. These vanes incorporate a Kiel probe at the leading edge for stagnation pressure, as well as a static pressure port at the throat (see Bach et al. [47] and the schematic in Fig. 1). Capillary tubes were inserted into the vanes that connect the pressure ports to the outside, following a path that exits through the trailing edge. Again, Kulite XTEL190 transducers were used to gather data from these ports. The uncertainty associated with the sensors is below $0.5 \%$ for a typical pressure reading. All transducers were also calibrated together with the complete measurement chain against a reference sensor to avoid a systematic error.

Data acquisition was carried out with a sampling rate of $500 \mathrm{kHz}$. Signal amplifiers were built in-house for the Kulite sensors, PCB sensors were connected to PCB-designed charge converters and amplifiers.

A high-speed camera was employed to capture video data of the flame luminosity at every operational point. The camera was placed next to the RDC and, through use of a mirror, looks upstream from the aft end into the combustor. For every test point, a series of 5000 images was taken at a rate of 87,500 frames per second, with an exposure time of $1 / 114286 \mathrm{~s}$. No specific wavelength filtering was applied as the natural luminosity of the flame proved sufficient for visualization.

676 individual tests were carried out across 12 configurations, with each run lasting for $200 \mathrm{~ms}$ after ignition. The run time was primarily limited to reduce the heat load on the Kiel probes and guide vanes. It was found that by about $150 \mathrm{~ms}$, the device had settled to a state of steady operation. Some $10 \mathrm{~ms}$ prior to ignition were also recorded to provide pre-run conditions with the flow of cold reactants. 


\subsection{Data treatment}

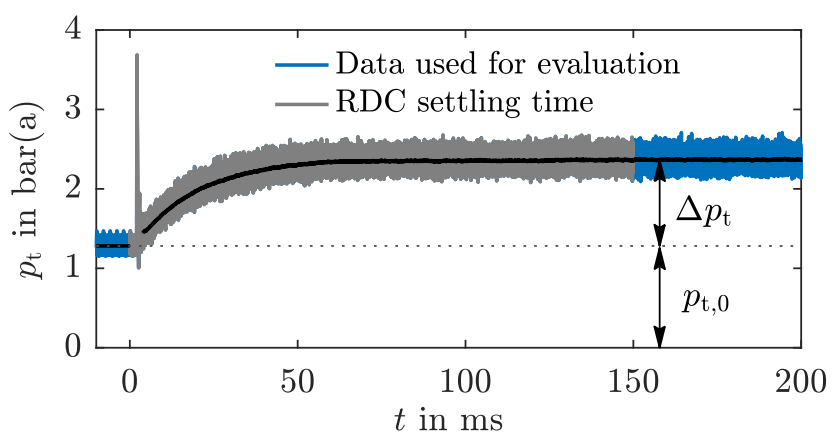

Figure 3: Representative time trace of stagnation pressure data obtained from a Kiel probe at the combustor outlet.

A generic mass flux notation is chosen in this manuscript to improve comparability of the results to other groups' experiments. This requires scaling of the mass flow with a representative area. Two different areas were chosen here: the combustion annulus cross-section $A_{\mathrm{c}}$ to obtain the combustor mass flux, $J_{\mathrm{c}}$, and the area at the outlet restriction, $A_{\mathrm{r}}$, to obtain the throat mass flux, $J_{\mathrm{r}}$.

Signals from the various pressure transducers and probes were conditioned prior to evaluation. For CTAP data it is assumed that after an initial rising period, the values accurately represent average conditions within the chamber. This has also been confirmed by parametric studies of different CTAP configurations [42]. The last $50 \mathrm{~ms}$ of each run, corresponding to about 250 individual cycles (depending on the operating mode), were averaged to obtain a mean static pressure value for each CTAP probe.

The same averaging method is applied to stagnation pressure data, which displays a behavior similar to that of the CTAP probes, albeit with a slightly 
longer rise time. An example of this is shown in Fig. 3. Again, the last $50 \mathrm{~ms}$ are averaged to obtain a value for the total pressure when combustion is occurring in the chamber. The data recorded for some $10 \mathrm{~ms}$ prior to ignition is also averaged and evaluated, and is noted as the total pressure in the flow of cold reactants through the annulus $\left(p_{\mathrm{t}, 0}\right)$ and allows further measurement of the pressure rise caused by combustion $\left(\Delta p_{\mathrm{t}}\right)$. Both parts of the time trace are highlighted in blue in Fig. 3. The gray segment in between represents the combustor settling time and is not used for evaluation. The approximate average value is also visualized in Fig. 3 by the black line, which applies a $1^{\text {st }}$-order Butterworth filter to the pressure trace. A metric for the pressure rise used in this study is the ratio $\Delta p_{\mathrm{t}} / p_{\mathrm{t}, 0}$.

Lastly, fluctuating static pressure (PCB) data are bandpass-filtered between $100 \mathrm{~Hz}$ and $50 \mathrm{kHz}$ to eliminate the low-frequency effects of thermal drift and possible interference from high-frequency components due to Helmholtz resonance in the recessed cavity holders. The low-pass frequency was found to be a reasonable compromise between the resolution of rising flanks in the signal attributed to passing combustion waves, and highfrequency noise.

Introducing a Kiel probe into a fluctuating transonic flow may lead to the formation of a normal shock upstream of the probe inlet, which in turn could result in a measurement error of stagnation pressure in the flow. The measured stagnation pressure will therefore always be smaller than the true stagnation pressure in supersonic flow. This loss is a function of the Mach number upstream of the shock and the ratio of specific heats (see, e.g. [48] for an overview of the thermodynamic relations across a normal shock). Previous 
studies have estimated the axial Mach number at an RDC's exit plane to vary between 0.9 and 1.3 [9], resulting in a maximum error of $3 \%$ in the stagnation pressure data. The averaging process in the Kiel probe and the viscous losses associated with the probe's internal geometry are not yet fully quantified and the subject of ongoing research efforts. It should be noted that the time-averaging induced by the Kiel probe conceivably also differs from the mass flow-averaging proposed in [9].

\subsection{Choked outlet flow}

The availability of stagnation pressure data from upstream of the combustor outlet unlocks the possibility to assess choking at the throat. Assuming ideal gas behavior, steady state choked flow occurs when the ratio of downstream pressure to upstream total pressure across the throat, $p^{*} / p_{0}$, falls below a critical value, which is only a function of the heat capacity ratio $\gamma$ of the gas (see, e.g., Yahya [48]):

$$
\frac{p^{*}}{p_{0}}=\left(\frac{2}{\gamma+1}\right)^{\frac{\gamma}{\gamma-1}}
$$

The $\gamma$ of the combustion gases varies mainly with temperature and gas composition. The range of $\gamma$ that is expected to be present in the experiment was calculated with NASA's CEA tool [49] to be within 1.164 and 1.229 (arising from the range of nominal equivalence ratios and chamber pressures that were studied). This in turn leads to a critical pressure ratio between 0.559 and 0.572 , which can be compared to the actual measured pressure ratio. As the RDC described here exhausts into the lab environment, the ambient pressure downstream of the throat (in the lab) is approximated to $p_{\text {amb }}=1$ bar. 


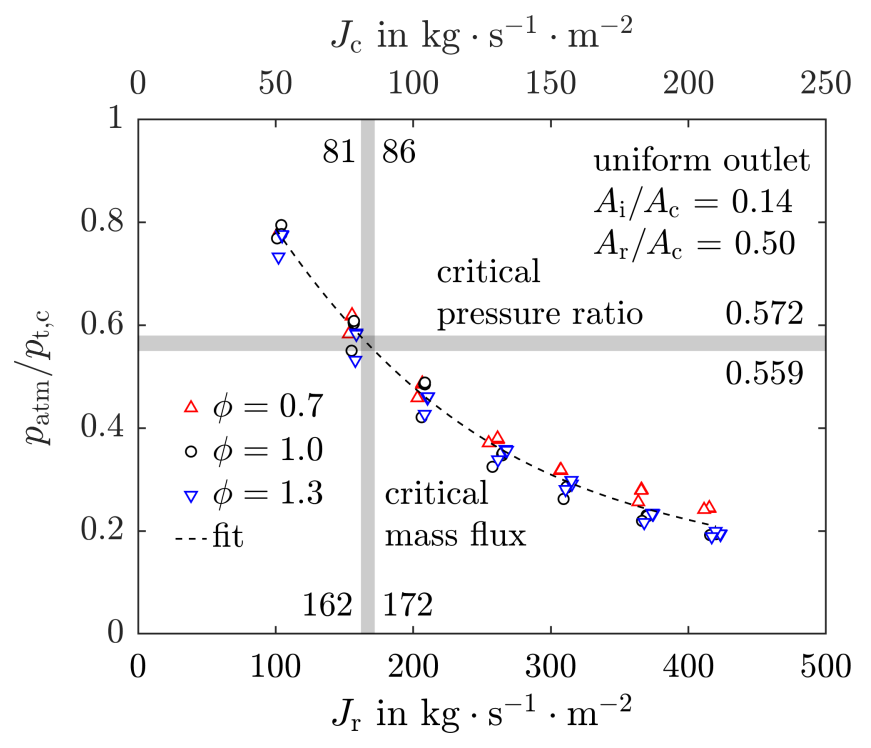

Figure 4: Example plot of pressure ratio across the outlet for one RDC configuration. The corridor where the polynomial fit intersects with the critical pressure ratio provides an estimate of the choking mass flux. Exact values of the upper and lower bounds are given for reference.
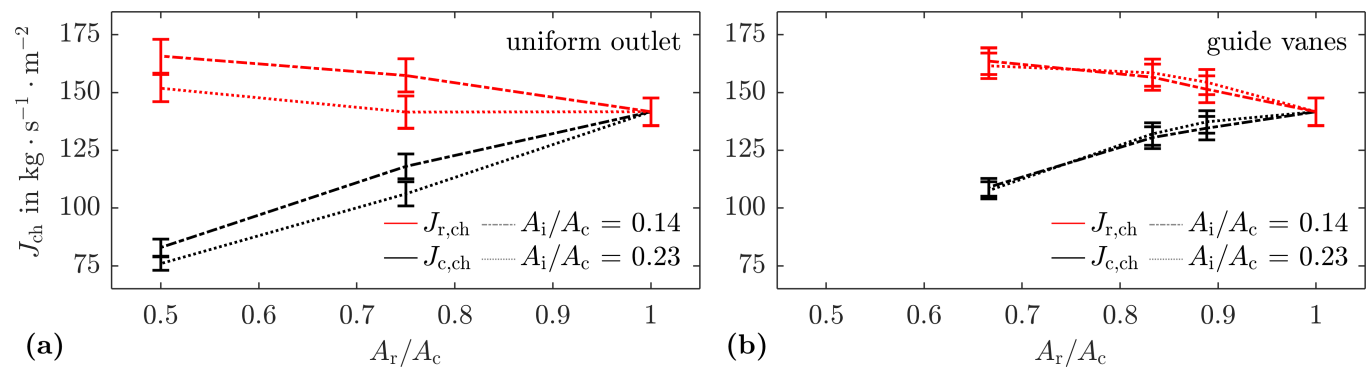

Figure 5: Critical mass flux over restriction area ratio for (a) uniform outlet and (b) guide vane setup. In (b), the data point for $A_{\mathrm{r}} / A_{\mathrm{c}}=1$ was reproduced from the uniform outlet configuration and plotted for reference only. 
An example comparing the measured pressure with the critical ratio is given in Fig. 4 for the uniform outlet setup with $A_{\mathrm{i}} / A_{\mathrm{c}}=0.14$ and $A_{\mathrm{r}} / A_{\mathrm{c}}=0.50$. In this figure, data for the ratio of ambient pressure, $p_{\mathrm{amb}}$ to the total pressure upstream of the restriction, $p_{\mathrm{t}, \mathrm{c}}$ are plotted over mass flux with differently shaped data points according to combustion stoichiometry. A third-order polynomial was fitted to the data and is also plotted, together with a horizontal gray band indicating the range of the critical pressure ratio. The critical mass flux that marks the transition to choked flow in the throat is designated by the vertical gray band, and was calculated from the intersection points of the polynomial with the lower and upper critical pressure ratio limits. This procedure was carried out for each configuration to obtain the critical mass flux during combustion, and the results are compiled in Fig. 5. In this figure, the critical mass flux is plotted in terms of both the combustion annulus mass flux, $J_{\mathrm{c}, \mathrm{ch}}$ (black curves), and the throat mass flux, $J_{\mathrm{r}, \mathrm{ch}}$ (red curves) over the throat area ratio $A_{\mathrm{r}} / A_{\mathrm{c}}$ for the uniform outlet (Fig. 5a) and guide vane setup (Fig. 5b). The different air injectors are distinguished by dash-dot (higher-loss injector) and dotted lines (lower-loss injector). The lines in both sub-figures connect the average critical mass flux values, with the vertical bars denoting the span caused by the uncertainty in exhaust flow $\gamma$. When the critical mass flux is mentioned in other sections of this manuscript, it is referring to the average value. In Fig. 5b, the point for $A_{\mathrm{r}} / A_{\mathrm{c}}=1.00$ was reproduced from the unrestricted uniform outlet data set for comparison. There is a deviation in the data for the two air injector types and the uniform outlet. The critical mass flux for the lower-loss injector is smaller than that for higher-loss injector when a uniform outlet blockage is 
present. This trend is not present for the guide vane setup. Due to variations in the operating mode and performance between the two different outlet geometries, the lower critical mass flux of the uniform outlet at a fixed outlet area ratio for different air injector area ratios indicates that this configuration results in a higher measured total pressure (i.e. choking at a lower mass flux). For the guide vanes, it seems that the discrete blockages of the vanes results in a different coupling with the air injector. Therefore, it appears that the air injector performance is somewhat more sensitive to the uniform outlet geometry than the guide vane configurations. For an unrestricted outlet at $A_{\mathrm{r}} / A_{\mathrm{c}}=1.00$, all curves coincide at the same point.

\section{Results}

The objective of this work is an assessment of RDC behavior at different inlet and outlet boundary conditions and outlet geometries over a range of operating points characterized by mass flux and equivalence ratio. This is done in conjunction with an analysis of the performance of the device through the quantification of stagnation pressure rise during combustion. The combination of these approaches sheds light on both current challenges and the path forward in RDC development. In this section, a brief description of the identified modes of operation is given, followed by a comprehensive mode progression map of TU Berlin's RDC. This discussion is necessary in order to understand the impact of the varying operating modes on RDC performance. Stagnation pressure data are then utilized to assess multiple characteristics of this device, with an estimate of pressure gain presented at the end. 


\subsection{Wave speed and mode identification}
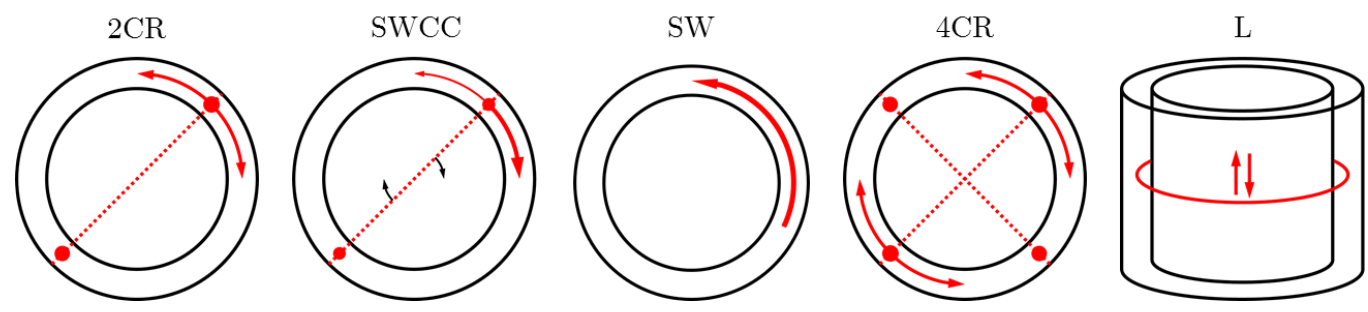

Figure 6: Illustration of mode shapes described in this study.

Identifying the correct wave speed and arrangement in the combustor is crucial to assessing the performance of the device. The most common approach, which is also employed here, is to use fluctuating static pressure data transformed into the frequency domain to identify dominant components. A comparison of the time traces of azimuthally and axially distributed sensors then allows differentiation between individual modes. The assumed wave arrangement can further be validated by analyzing high-speed video of the flame luminosity [39]. Both methods were applied to the data in this study. The frequency at which combustion waves propagate in the annulus can then be converted to a velocity by using the mean path length in the combustion annulus. For a more meaningful measure, the estimated velocity is expressed in relation to the ideal Chapman-Jouguet (CJ) velocity, which itself is a function of the conditions within the combustor, $v_{\mathrm{CJ}}\left(p_{\mathrm{s}}, T, \phi\right)$. The CJ velocity was calculated using NASA's Chemical Equilibrium with Applications (CEA) tool [49]. The initial conditions supplied to the algorithm are $p_{\mathrm{s}}$, the

static pressure in the combustor during operation as measured by a CTAP probe in the combustion zone, $T$, the temperature of reactants prior to injection, and $\phi$, the nominal equivalence ratio. While $T$ and $\phi$ will be influenced 
by the complex combustor flow field, the use of nominal values was chosen to provide a consistent metric. The CEA tool further provides a host of other information, of which the speed of sound in the burned gas, and the ratio of specific heats of the products, $\gamma$, are used for analysis in this study. Both values are influenced by the gas condition ahead of the reaction as well as the mode of combustion (deflagration or detonation). The resulting difference is however relatively minor. From the evaluated data and past experience with this combustor, five canonical modes of the RDC device are commonly observed and are described in the following sections. Variations of these modes exist as a mixture or transition between the ones presented here, and a more detailed description is provided by Bluemner et al. [50]. However, within the scope of this study, grouping the operation into five main modes allows for a more practical comparison between the individual RDC configurations. The operational modes are described in the following and the cartoons illustrated in Fig. 6 help clarify the processes. While the term combustion wave is generally applied to the observed phenomena, it is unlikely that all of these can be properly classified as detonations. In a number of cases, the reaction fronts are more similar to fast-moving choked deflagrations or to shock waves processing through the flame. Additionally, in all cases, the propagation velocity is always significantly less than the estimated CJ velocity, and the measured peak pressures of passing combustion waves are below the estimated CJ pressure. This is however typical for RDCs and was observed in numerous other experiments as well (for example Kindracki et al. [51] or St. George et al. [52]).

Two counter-rotating waves at equal speed (2CR): This mode, 
also called clapping or slapping mode, is encountered at the lower end of the mass flux range. It exhibits two waves propagating at approximately the speed of sound in the combustion products. Their low velocity suggests that the observed waves are choked deflagration fronts rather than detonations. Two distinct, fixed points exist in the annulus where both waves meet one another. As the flow rate is increased, the axis of intersection is observed to begin to precess as one of the waves strengthens and becomes faster relative to the other. In the context of this study, such behavior is still classified under the $2 \mathrm{CR}$ moniker.

Single wave with counter-rotating components (SWCC): As the mass flux is further increased, one wave becomes more dominant and its speed increases to well above the speed of sound in the burned gas and a significant fraction of the CJ velocity. This suggests quasi-detonative behavior for the dominant wave. The second wave weakens, while typically remaining near the estimated speed of sound. In these conditions, it is difficult to identify a clear counter-rotating wave in the pressure traces, however a smaller, distinct peak is still present in the spectrum. In the high speed video, these waves are often only weakly observable, but their interaction with the primary wave is clearly visible. Several different arrangements have been observed, with pairs or triplets of counter-rotating waves. All of these are here summarized under the SWCC category.

Clear single wave (SW): Eventually, the contribution of the counterrotating components to the overall spectrum becomes negligible and the combustor exhibits only one dominant single wave, in conjunction with a further increase of the wave speed, up to $84 \%$ of CJ velocity in the RDC presented 
here.

Two pairs of counter-rotating waves (4CR): Regimes where multiple waves co-rotate have been reported for other experiments in the past. This phenomenon can presumably be linked to a self-correcting mechanism within the combustor as the wave height becomes large (see St. George et al. [53]). In the present study, a further transitioning from a single wave to two pairs of counter-rotating waves is observed. This behavior is similar to the $2 \mathrm{CR}$ mode, but with twice the number of waves. The dominant frequency in the spectrum is well above the CJ speed, but needs to be divided by 2 to obtain the correct wave propagation velocity, as two waves pass by the sensor in one cycle. The resulting real wave speed falls to values slightly above the speed of sound in the burned gas again, similar to that observed for the $2 \mathrm{CR}$ mode. As this mode occurs when the mass flux is increased above the SW regime, it may be the beginning of the transition to two co-rotating waves. Unfortunately however, the mass flow capabilities of the laboratory are not currently sufficient to verify this hypothesis. It can also be speculated that the combination of physical combustor dimensions (diameter and length with a ratio close to unity, and a high aspect ratio annular channel), reactants and detonation cell size, and annulus mass flux for this specific device does not result in multiple co-rotating detonation heads without secondary phenomena under these conditions.

Axially pulsing combustion (L): For some operating and boundary conditions, a longitudinally pulsing combustion process is exhibited by the device (similar observations have been made, e.g., by Anand et al. [54] or Frolov et al. [55]). The observed spectrum is similar to that of the $2 \mathrm{CR}$ mode, 
however there is no clear azimuthal propagation. However, high-speed video indicates a uniformly distributed reaction around the entire combustor and axially distributed pressure sensors indicate the passage of pressure waves along the length of the combustor. Additionally, it is observed that further increasing the reactant mass flow is not observed to affect the wave speed as is observed in rotating waves.

\section{2. $R D C$ mode progression}

From the observations above, variations in the combustor geometry and operating condition can result in significant variations from the canonical, single wave description of the RDC. Combining wave speed data with information about the observed mode for each run results in the ability to track the RDC's behavior as a function of these parameters, and is shown in Fig. 7. This figure summarizes the behavior exhibited by the model RDC as boundary and operating conditions are varied. Each data point represents the propagating velocity of the dominant wave (in the mid-channel) relative to the specific CJ velocity. The horizontal axis in each sub-figure denotes the mass flux at the throat. Marker type and color indicate the equivalence ratio $(0.7,1.0$, and 1.3$)$. Two dashed lines are plotted for reference: a horizontal line indicating the speed of sound in the combustion products, and a vertical line indicating the mass flux at which the restriction becomes choked (measured according to the procedure discussed in Section (2.5)).

Figure 7 is arranged such that each row represents one configuration with a specific outlet type and air injector (constant $A_{\mathrm{i}} / A_{\mathrm{c}}$ ) combination. The two upper rows compare uniform outlet and guide vane setup with the more restrictive air injector $A_{\mathrm{i}} / A_{\mathrm{c}}=0.14$, while the two lower rows do the same for 

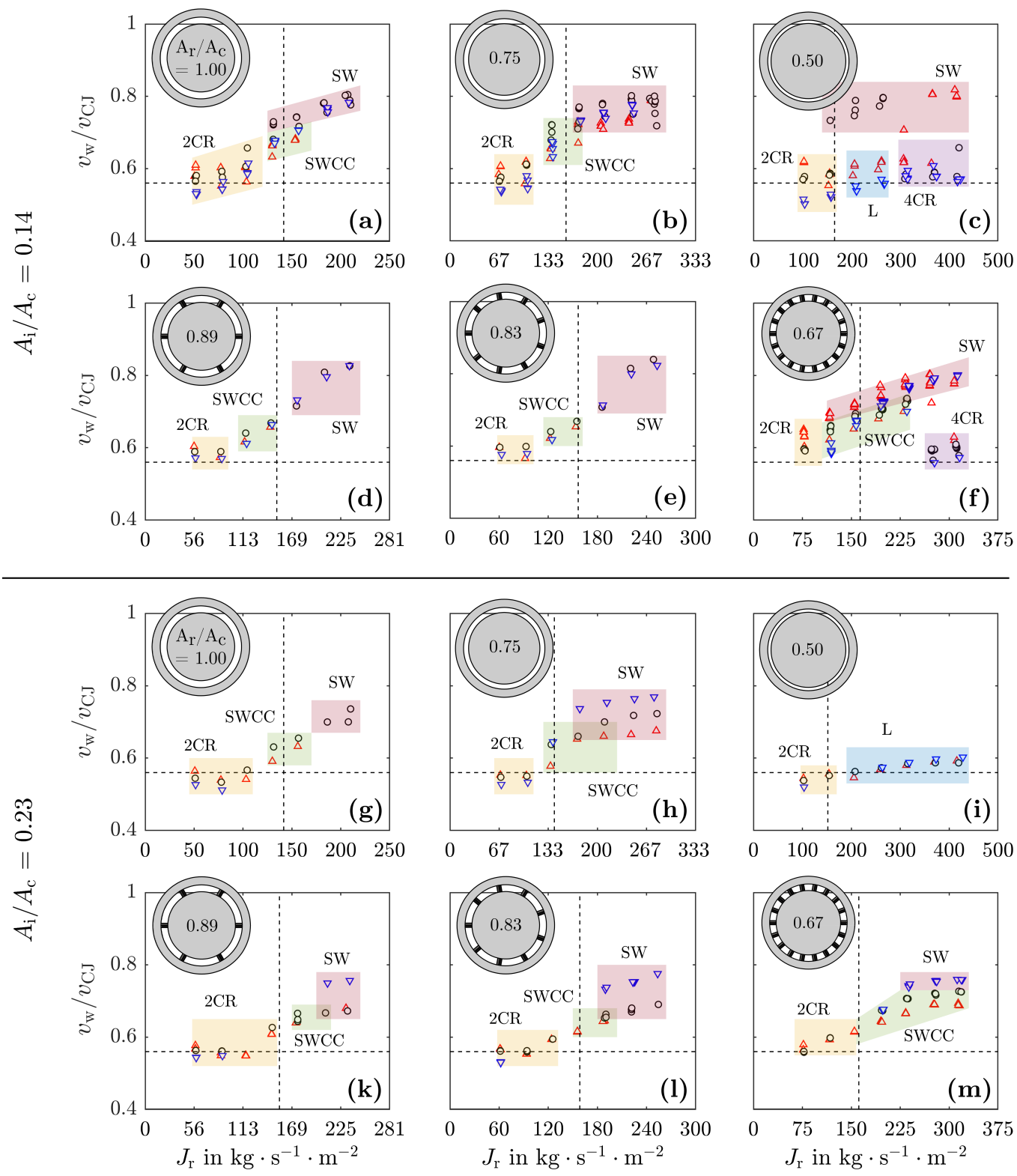

Figure 7: Speed $v_{\mathrm{w}}$ of dominant combustion wave in relation to CJ velocity as a function of throat mass flux $J_{\mathrm{r}}$ and equivalence ratio $\phi$ (red triangles for $\phi=0.7$, black circles for $\phi=1.0$ and blue triangles for $\phi=1.3$ ) for investigated RDC configurations. (Continued on next page) 
Figure 7: (Continued from previous page.) Figures are sorted by injector area ratio (from top to bottom) and restriction area ratio (decreasing from left to right). Shaded areas represent the dominant observed mode with light yellow for $2 \mathrm{CR}$ mode, light green for SWCC mode, light red for SW mode, light purple for $4 \mathrm{CR}$ mode, and light blue for L mode. For reference, a dashed horizontal line represents the speed of sound in the combustion products and a dashed vertical line the mass flux at which the outlet becomes choked.

the larger $A_{\mathrm{i}} / A_{\mathrm{c}}=0.23$. From left to right, the throat to annulus area ratio $A_{\mathrm{r}} / A_{\mathrm{c}}$ decreases as the outlet becomes more restricted. Differently shaded regions indicate the dominant mode exhibited by the RDC as described in subsection 3.1 above. 2CR behavior is represented by light yellow, SWCC by light green, SW by light red, and $4 \mathrm{CR}$ by light purple. Light blue was chosen for the L mode. All regions are also labeled accordingly.

A typical modal progression is displayed for the configuration in Fig. 7a. At the lower end of the operating range, the RDC behavior is classified as $2 \mathrm{CR}$ with two waves propagating near the speed of sound in the combustion products. As thermal power is increased, so too is the wave velocity until one of the two waves starts to become more dominant, after which the RDC transitions to the SWCC mode. At this point, the wave velocity is well above the speed of sound and continues to increase as the device switches to the SW mode. The mechanism of mode transition is complex and dependent on a number of factors. Reactant fill height increases with mass flux and promotes the development of stronger waves travelling at higher velocity, as indicated by the difference in the $2 \mathrm{CR}$ and SWCC regions. Outlet choking additionally increases the chamber pressure and thereby lowers the bulk flow velocity and the fill Mach number, which was shown to result in stronger detonative 
behavior [13]. For this reason, in most configurations the transition region towards single wave behavior coincides with the mass flux at which the outlet becomes choked. At the upper end of the mass flux range, a wave speed of about $80 \%$ CJ is attained. Only small quantitative differences were observed between the different equivalence ratios.

A $25 \%$ outlet restriction is introduced in Fig. $7 \mathrm{~b}$. An assessment in terms of the restriction mass flux reveals that the behavior is indeed similar to that of the unrestricted case, but with an extended mass flux range up to $J_{\mathrm{r}}=280 \mathrm{~kg} \cdot \mathrm{s}^{-1} \cdot \mathrm{m}^{-2}$. This leads to a larger single wave region with wave speeds again at about $80 \%$ CJ. The transition region again coincides with the critical mass flux as pointed out above. Operating points at stoichiometric conditions display higher wave speeds than either lean and rich cases.

Further increasing the outlet restriction to $50 \%$ again changes the RDC behavior (Fig. 7c). The device exhibits three distinct transition paths for lean, stoichiometric, and rich conditions once the $2 \mathrm{CR}$ region is left. For stoichiometric conditions, a similar progression as before towards clear single wave behavior is observed. Increasing the mass flux above a certain point (around $J_{\mathrm{r}}=300 \mathrm{~kg} \cdot \mathrm{s}^{-1} \cdot \mathrm{m}^{-2}$ ) leads to a branching off of the single wave into two pairs of counter-rotating waves (4CR), which is sustained up to the maximum mass flux. The wave speed exhibits a step change when the mode shifts, again towards the speed of sound in the combustion products, but then gradually increases again with mass flux. This indicates that the $4 \mathrm{CR}$ mode observed here is potentially another transition region towards clear two co-rotating wave behavior. For lean conditions, a first transition happens from $2 \mathrm{CR}$ to an axially pulsing (longitudinal, L mode) combustion 
process once the critical mass flux is exceeded. Then the RDC shifts from $\mathrm{L}$ to SW, accompanied by a significant increase in wave speed. There are three outliers present in the map (lean cases located in the $4 \mathrm{CR}$ region). These points are attributed to the $\mathrm{L}$ mode, but for reasons of readability the two regions where not displayed as overlapping. Finally, a mix of both pathways is observed for rich conditions, where at first the transition from $2 \mathrm{CR}$ to $\mathrm{L}$ happens, but instead of shifting to an SW mode later on, the device directly moves towards the $4 \mathrm{CR}$ region, again with wave speeds nearer the speed of sound in the products.

The guide vane combustor with $A_{\mathrm{i}} / A_{\mathrm{c}}=0.14$ exhibits similar behavior, as displayed in Fig. 7d-f. A progression from 2CR over SWCC towards SW can be identified with similar trends as before and a maximum wave velocity of $84 \%$ CJ. For high throat restriction, the transition from SW to $4 \mathrm{CR}$ is observed as well, however no axially pulsing combustion was encountered as the restriction is not as high as in the uniform case of $50 \%$. This may also be influenced by the vane stage's increased ability to ingest pulsations and/or reduce coherent reflections from the outlet.

Decreasing the injector pressure loss for the uniform outlet configurations (Fig. 7g-i) has several effects on the RDC's behavior. A lower wave speed is achieved throughout the mass flux range and the transition to single wave behavior occurs at a higher mass flux than before. For increased throat restriction, a clear dependence of wave speed on the equivalence ratio can be observed once the threshold to enter the single wave regime has been crossed. For the $A_{\mathrm{r}} / A_{\mathrm{c}}=0.50$ case, the RDC transitions from $2 \mathrm{CR}$ to $\mathrm{L}$ mode behavior at the critical mass flux, and does not leave this region up to 
the end of the operating range. In that case the significant throat restriction more easily enables plenum coupling through the larger inlet area. For the guide vane setup (Fig. 7k-m), a steady progression from 2CR to $\mathrm{SW}$ behavior is observed, but again the measured wave speeds are lower than those of the higher-loss injector. For the smallest $A_{\mathrm{r}} / A_{\mathrm{c}}$ value (Fig. $\left.7 \mathrm{~m}\right)$, no transition towards $4 \mathrm{CR}$ could be identified within the flow rate range studied.

In summary, both the mode of combustion and the attained wave speed depend significantly on the configuration and operating point of the device. In the following, this information will be linked to the measured stagnation pressure rise to assess the influence of the operational mode on RDC performance.

\subsection{Stagnation pressure rise}

This section presents the stagnation pressure rise associated with the combustion process. While the results are specific to the studied geometry, they can be used as a metric for combustor performance and to observe the effects of mass flux and combustor operating mode. The findings are summarized in Fig. 8, where the increase in total pressure during combustion, $\Delta p_{\mathrm{t}}$, relative to the initial total pressure before combustion, $p_{\mathrm{t}, 0}$, is shown (see Section 2.4 for details).

As the pressure sensor in the Kiel probe is separated from the measurement point by a capillary tube (similar to the CTAP), only the average value of the pressure time trace, not the dynamic content, is used for evaluation. Therefore, no information about the variation of stagnation pressure over one period of RDC operation is discussed. The data presented in this section were gathered with a Kiel probe immediately upstream of the uniform out- 

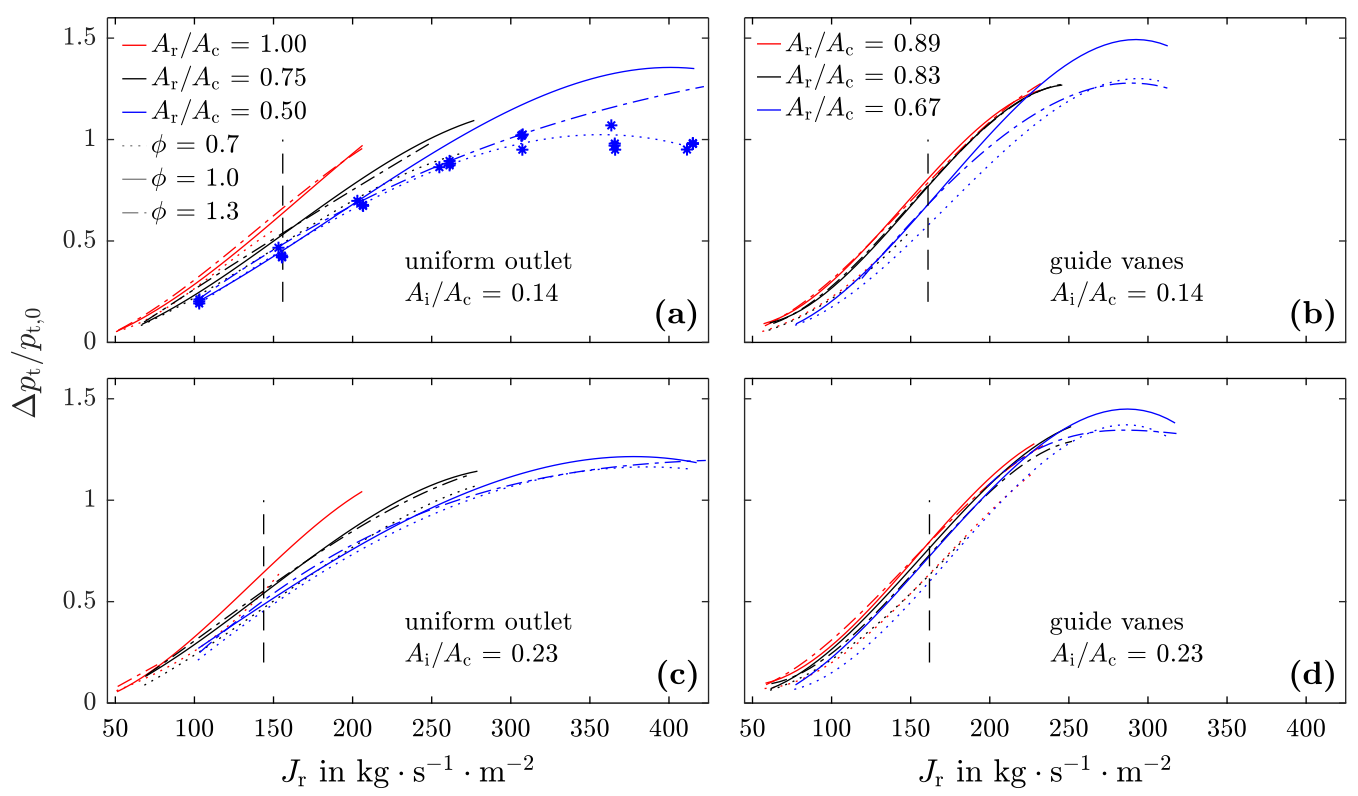

Figure 8: Stagnation pressure rise as a function of throat mass flux for investigated RDC configurations. The vertical dashed line represents the mass flux at which the outlet becomes choked. Plotted curves are polynomial fits of the scattered data. An example data set for $A_{\mathrm{i}} / A_{\mathrm{c}}=0.14, A_{\mathrm{r}} / A_{\mathrm{c}}=0.50, \phi=0.7$ is shown to underline the goodness of fit. 
let restriction and from the Kiel probe embedded in the instrumented guide vane. For readability, polynomials were fitted to each set of data points characterized by outlet type, blockage $A_{\mathrm{r}} / A_{\mathrm{c}}$, equivalence ratio $\phi$, and air injector $A_{\mathrm{i}} / A_{\mathrm{c}}$. In Fig. 8 , these polynomials for the $\Delta p_{\mathrm{t}} / p_{\mathrm{t}, 0}$ value are plotted over the throat mass flux $J_{\mathrm{r}}$ in four sub-figures. Three groups of curves of different color show the influence of the outlet blockage, with $A_{\mathrm{r}} / A_{\mathrm{c}}$ descending with increasing restriction. Within one set of curves, the line style indicates different equivalence ratios. Fig. 8a\&b report data for $A_{\mathrm{i}} / A_{\mathrm{c}}=0.14$, and Fig. $8 \mathrm{c} \& \mathrm{~d}$ data for $A_{\mathrm{i}} / A_{\mathrm{c}}=0.23$. An example data set is plotted in Fig. $8 \mathrm{a}$ to underline the goodness of fit. As all of the obtained $R^{2}$ values are above $96 \%$, reducing the scattered data to fitted curves is intended to simplify the interpretation of the results. A vertical line is also given for reference, representing the approximate value of the critical mass flux above which the outlet becomes choked.

Figure 8a shows the results from the uniform outlet setup with the more restrictive injector. Plotting the pressure rise over the throat mass flux collapses the individual curves. In the lower mass flux region, the influence of equivalence ratio on the stagnation pressure rise is mostly negligible. Only at high $J_{\mathrm{r}}$ does the influence of stoichiometry become significant, with the rich and lean conditions producing a lower pressure rise relative to stoichiometric operation. Recalling the observations made in the previous section, this specific region demonstrates a difference in operating mode. Both stoichiometric and rich cases were seen to switch to a $4 \mathrm{CR}$ behavior, while lean conditions still showed SW propagation. It appears that the operating mode - for a high mass flux at the throat - does influence the stagnation pressure 
rise in the combustion process. A second observation is that the pressure rise increases steadily with mass flux up to a point, after which further increasing the mass flux no longer results in a corresponding increase in the pressure rise. This indicates that, from a design standpoint, the performance of a specific combustor may experience diminishing performance returns with increasing mass flux. Lastly, increasing the outlet restriction resulted in a reduction in the measured relative pressure rise, due to the increase in the initial combustor total pressure before combustion. Therefore, since total pressure losses across the injector will continue to increase with increasing combustor pressure without the corresponding increase in total pressure rise, the operational design point should recognize the desired outlet restriction ratio when sizing the combustor in order to avoid these competing effects.

For the guide vane setup with the same injector (Fig. 8b), a similar but steeper pressure rise is obtained throughout the mass flux range. The steeper gradient may be attributable to the reduction in the $2 \mathrm{CR}$ operating region in the guide vane configuration as well as a reduced impact on the combustion due to reflections from the outlet. Compared with the uniform outlet case, the guide vane configuration shows less variation between the different outlet restrictions across the mass flux range. The guide vane configuration also exhibits a greater maximum measured pressure rise compared with the uniform outlet, which is likely due to the qualitatively better operation (i.e. suppression of the $2 \mathrm{CR}$ and $\mathrm{L}$ modes as observed in the uniform outlet case and the slightly higher wave speeds). Overall, it appears that the guide vane configuration is more conducive to obtaining a larger pressure rise than the more blunt uniform outlet restrictions. 
Increasing the air injector area, as shown in Fig. 8c\&d, leads to similar behavior for both configurations, with a steady increase in stagnation pressure rise at first before levelling off at the upper mass flux range. There is less of a difference between cases at different equivalence ratios for high mass fluxes, which can be traced back to the fact that this injector did not exhibit mode transition from SW to $4 \mathrm{CR}$. It can also be seen that even when the $\mathrm{RDC}$ is operating in $\mathrm{L}$ mode (e.g. for uniform outlet with $A_{\mathrm{r}} / A_{\mathrm{c}}=0.50$ and $J_{\mathrm{r}}>200 \mathrm{~kg} \cdot \mathrm{s}^{-1} \cdot \mathrm{m}^{-2}$ ), there is still a substantial stagnation pressure rise, suggesting that the performance may not be too negatively impacted by these non-ideal operating modes. For the uniform outlet, the obtained $\Delta p_{\mathrm{t}} / p_{\mathrm{t}, 0}$ values are slightly lower (circa 10\%) for this injector compared to the previous one. This difference is not observed for guide vane configurations.

\subsection{Combustion chamber Mach number}

In order to assess the performance and flow properties of an RDC, it is desirable to obtain an estimate for the Mach number in the chamber. From the isentropic flow equations of a converging-diverging nozzle with a choking condition at the throat (see, e.g., [48]), a Mach number can be computed iteratively using a simple root-finding algorithm. This Mach number is then only a function of $\gamma$ and the ratio of flow to throat area,

$$
\frac{A}{A^{*}}=\left(\frac{\gamma+1}{2}\right)^{-\frac{\gamma+1}{2(\gamma-1)}} \frac{\left(1+\frac{\gamma-1}{2} \mathrm{M}^{2}\right)^{\frac{\gamma+1}{2(\gamma-1)}}}{\mathrm{M}}
$$

Similarly, a Mach number can be calculated from the ratio of measured static to total pressure of the flow, 

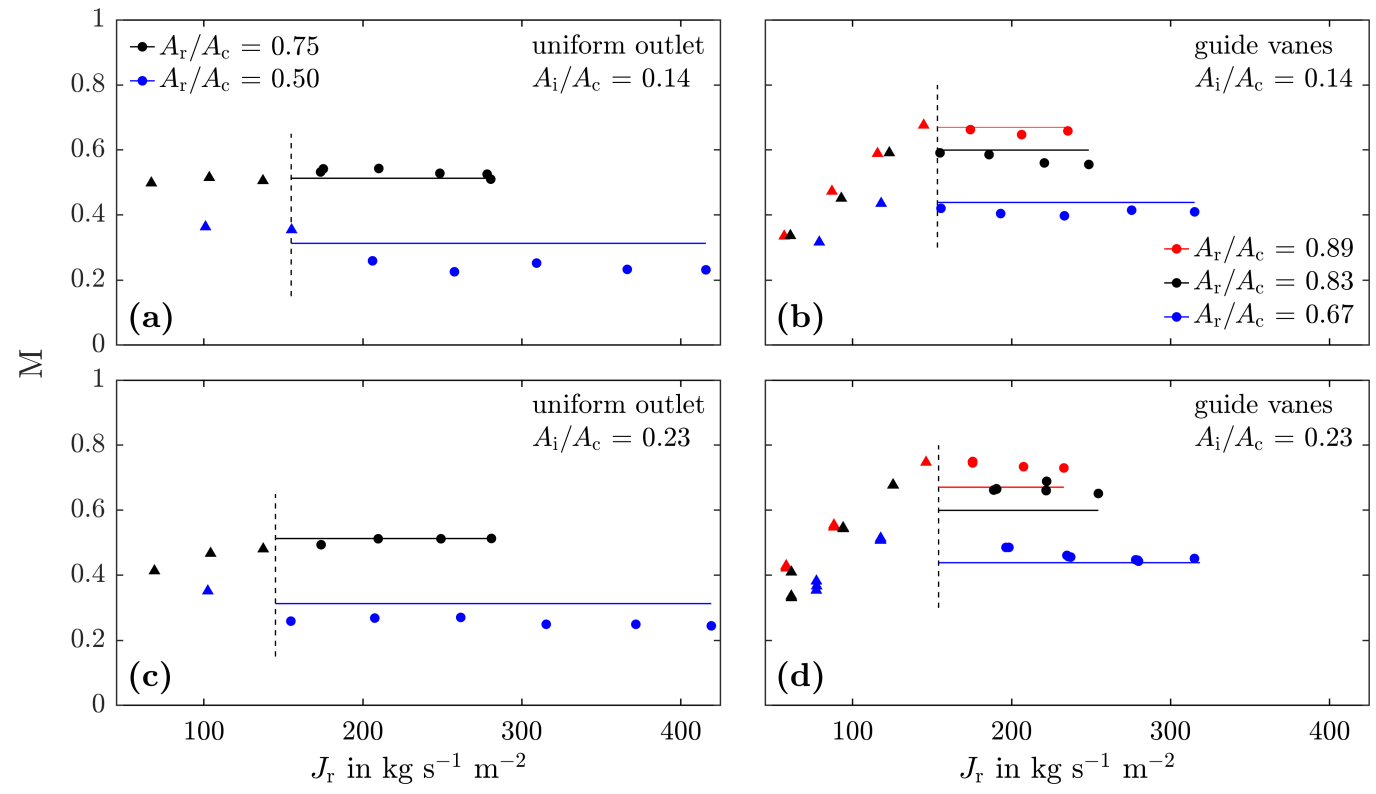

Figure 9: Comparison of area ratio based Mach numbers (solid lines) and experimentally determined Mach numbers (markers) for individual configurations at stoichiometric conditions. A dashed vertical line represents the mass flux at which the outlet becomes choked. Triangles denote operating points below the choking mass flux based on the measured pressure ratio, while circles denote operating points at which the outlet is considered choked. 


$$
\frac{p_{\mathrm{s}}}{p_{\mathrm{t}}}=\left(1+\frac{\gamma-1}{2} \mathrm{M}^{2}\right)^{-\frac{\gamma}{\gamma-1}}
$$

In this section, a comparison of these two values, the area ratio-based Mach number and the measured pressure ratio-based Mach number is made. It should be noted that these flow relations were derived for steady state, isentropic flow and are applied here to a highly unsteady, transonic flow, and so the presented values should only be considered as estimates.

The pressure ratio of the uniform outlet setup was calculated from a CTAP probe about $10 \mathrm{~mm}$ upstream of the outlet throat, and the Kiel probe's stagnation pressure data. For the guide vane setup, the vane-integrated Kiel head (at the leading edge) was used together with a CTAP probe $10 \mathrm{~mm}$ upstream of the leading edge. Figure 9 plots the comparison for all configurations at a nominal equivalence ratio of 1.0. The solid lines represent the area ratio-based Mach numbers, which are effectively constant and enforce a strong assumption of a steady sonic condition at the throat. Markers represent experimentally determined Mach number values. The data is presented with two different markers, indicating values that are below (triangles) and above (circles) the critical mass flux (dashed vertical lines).

There is a good agreement between the two Mach number estimates across all four configurations and $A_{\mathrm{r}} / A_{\mathrm{c}}$ values at higher mass flux values. As the area ratio-Mach number relation is only valid once a choking condition is established at the throat, it is not very useful to perform this comparison at lower mass flux values and one should avoid assigning too much emphasis to these lower end values. But as can be seen, the Mach number can vary significantly below the critical mass flux, especially for the guide vane 
setup in Fig. 9b\&d. From this figure, one can see two important conclusions. First, the channel Mach number is primarily a function of the outlet restriction. Increasing this outlet restriction significantly decreases the outlet Mach number. However, for less restricted outlets, the Mach number can be quite high (up to 0.8 in the results here). This indicates the importance of carefully engineering the downstream flow path in order to utilize this high Mach number flow without suffering further total pressure losses. Second, the measured pressure ratio-based channel Mach number is generally independent of the mass flux, implying a corresponding increase in the channel static pressure. Such a variation is likely to impact the mixing and reactant injection process, and subsequently the combustor performance. Therefore, it is further highlighted that a proper RDC design will require the balancing of these Mach number effects with the reactant injection and throttling capabilities.

\subsection{Pressure gain estimate}

Quantifying the pressure gain of the combustion process, in order to assess the RDC's performance under various boundary conditions, requires comparison of two stations in the flow: one upstream and one downstream of the location where combustion is established. One approach was described in Section 3.2, where the stagnation pressure rise due to combustion was compared to the total pressure measured before combustion. This, however, neglects the initial cost of pressure loss that occurs over the reactant injectors and which is required for reactant mixing. Only the rise in stagnation pressure that overcomes this initial investment can be considered the pressure gain of the device. In this section, an attempt is made at quantifying 

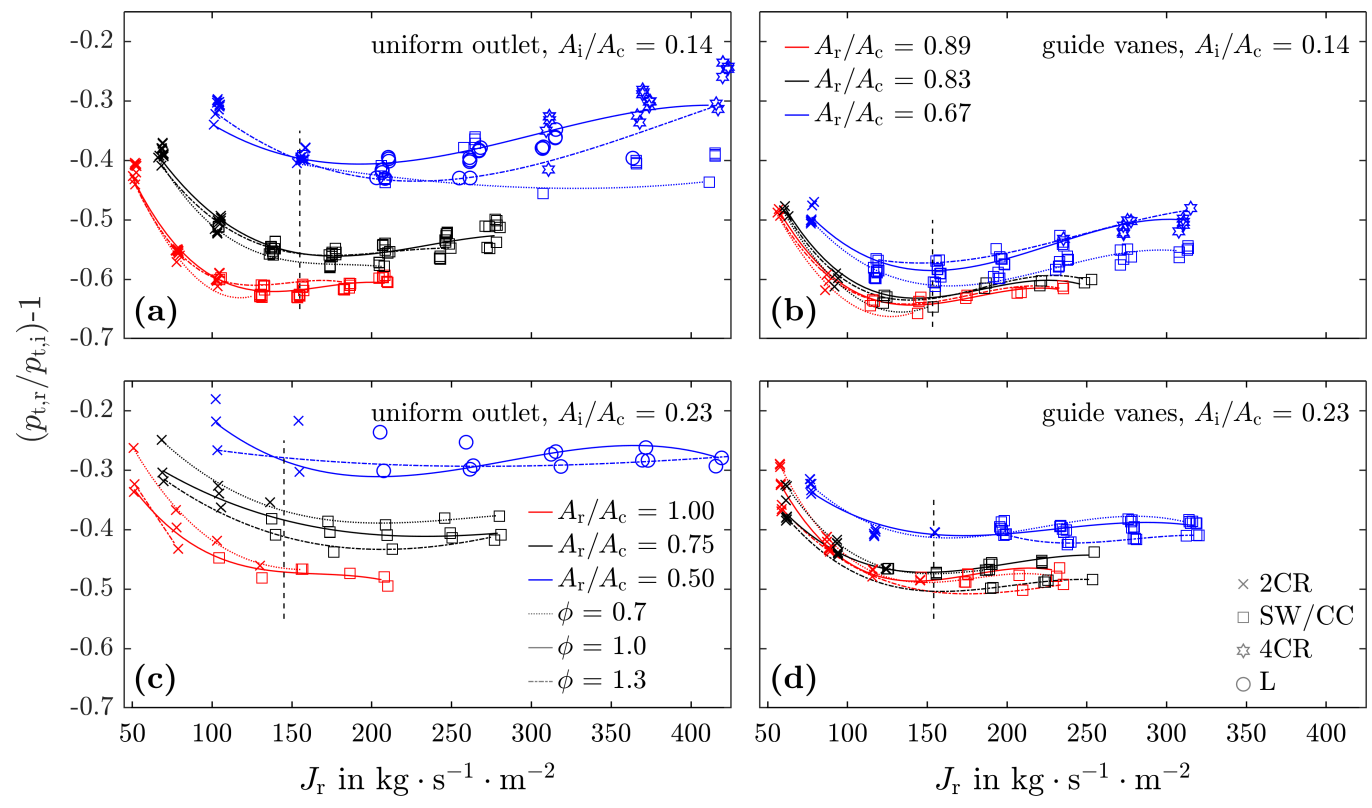

Figure 10: Estimates of stagnation pressure gain between air plenum and outlet throat for the investigated configurations. A dashed vertical line represents the mass flux at which the outlet becomes choked. Plotted curves are polynomial fits of the scattered data. The overlayed markers represent the observed operating mode, with crosses symbolizing $2 \mathrm{CR}$ or $2 \mathrm{CRT}$ behavior, squares SWCC or SW behavior, hexagrams $4 \mathrm{CR}$ behavior, and circles longitudinally pulsing combustion (L mode). 
the pressure gain based on the available stagnation pressure data. A static pressure sensor in the air plenum of the RDC (the location marked $p_{\mathrm{A}}$ in Fig. 1) is employed to obtain a measure of the stagnation pressure prior to injection. As the sensor is placed at a location in the plenum where flow velocity is low $(\mathrm{M} \leq 0.05)$, static pressure accounts for more than $99.7 \%$ of the stagnation pressure and is therefore a reasonable representation of the stagnation pressure. In the following, the pressure gain (PG) is expressed as $\left(p_{\mathrm{t}, \mathrm{r}} / p_{\mathrm{t}, \mathrm{i}}\right)-1$ with $p_{\mathrm{t}, \mathrm{i}}$ the stagnation pressure in the air plenum, and $p_{\mathrm{t}, \mathrm{r}}$ the stagnation pressure just upstream of the RDC's outlet throat. The data are presented in Fig. 10 in the same way as previously in Sections 3.2 and 3.3 with four individual sub-figures for the four outlet/injector combinations. Casting the results in this way leads to more differentiated insights than before (cp. Fig, 8). In addition to the interpolated polynomial curves, data points for the observed operating mode are also plotted in the figure. This allows for an assessment of the operating mode's influence on the achieved pressure gain. For all configurations, the pressure gain curve at first decreases until the transition from $2 \mathrm{CR}$ to SWCC behavior occurs. This coincides approximately with the operating point at which a choking condition at the outlet is established. Increasing the mass flux beyond this point then results in a different operating mode and also in an infliction of the curves. Most configurations then display a positive gradient. The subsequent analysis therefore focuses on the mass flux range above the choking condition.

Pressure gain curves for the uniform outlet setup with the higher-loss injector are displayed in Fig. 10a. The positive influence of increasing throat restriction is clearly visible as the pressure gain drastically increases from 
the curve for $A_{\mathrm{r}} / A_{\mathrm{c}}=1.00$ to the one for $A_{\mathrm{r}} / A_{\mathrm{c}}=0.50$. Also visible is the positive influence of higher thermal power, as in most cases pressure gain increases with mass flux. For the bulk of the mass flux range, there is no discernible difference between lean and rich conditions. At high mass flux, and for a very restricted outlet, however, the curves deviate as was also seen before in the stagnation pressure rise data. This is interpreted to be associated with a change in operating mode as the RDC transitions towards $4 \mathrm{CR}$ behavior. Using a lower-loss injector with the uniform outlet configuration (Fig. 10c) consistently leads to higher pressure gain values throughout the whole operating range. This is expected as the $p_{\mathrm{t}, \mathrm{i}}$ term is smaller. Variations in the equivalence ratio further lead to a more discernible difference in the pressure gain curves, especially for the $A_{\mathrm{r}} / A_{\mathrm{c}}=0.75$ case. A similar observation was made earlier with regard to the detonation efficiency in terms of wave speed (Fig. $7 \mathrm{~h}$ ). Since no transition to multiple waves was observed, the pressure gain curves stagnate at high mass flux. It was shown that this specific RDC tends to lock into a sustained longitudinally pulsing combustion mode at $A_{\mathrm{r}} / A_{\mathrm{c}}=0.50$, which appears to result in more or less constant pressure gain.

For the guide vane setup with the higher-loss injector (Fig. 10b), similar trends can be observed, validating the previous interpretation. The range of outlet restrictions is not as wide as for the uniform outlet case, but the results do indeed line up well. The effects of $A_{\mathrm{r}} / A_{\mathrm{c}}$ and mass flux are the same as the uniform configuration. Variations in equivalence ratio have a different effect, as the performance of lean cases falls short of those at stoichiometric or rich conditions. Indeed, lean operation could not be established at higher mass 
flux, except for $A_{\mathrm{r}} / A_{\mathrm{c}}=0.67$. But also there, lean cases display lower pressure gain along the whole mass flux range. Again, as the RDC switches to multiple waves, a further increase in pressure gain is detected for high-restriction, highmass flux conditions at stoichiometric or rich equivalence ratios. For lean cases, the pressure gain is lower. The lower-loss injector performs comparably as shown in Fig. 10d. Lower injector losses lead to overall higher pressure gain values and the influence of mass flux is discernible. Another interesting observation is the inferior performance of rich cases, which is consistently lower than the values attained by stoichiometric or lean equivalence ratios at the upper mass flux range. Rich conditions in this configuration led to a dominant single wave with high propagating velocity (about $80 \%$ CJ). As Heat release under confinement is the defining characteristic of pressure gain, lean and rich combustion conceptually present two different pathways. For lean conditions, the total heat release can occur within the combustor at the cost of additional diluents. In rich cases, only incomplete heat release occurs within the combustor. These two pathways can reasonably result in differences in pressure gain. It can be summarized from these observations that while injector loss and outlet configuration do play a major role in the establishment of pressure gain and its magnitude, the operating mode of the RDC at mass fluxes sufficient to choke the outlet is important to unlock the potential. Another conclusion from these data is that wave speed alone is not a sufficient metric for assessing the performance of an RDC.

In the numerical work of Kaemming and Paxson [9], the authors employ the equivalent available pressure (EAP) metric which relates the outlet flow's averaged stagnation pressure to ideal exit velocities that could be used for 


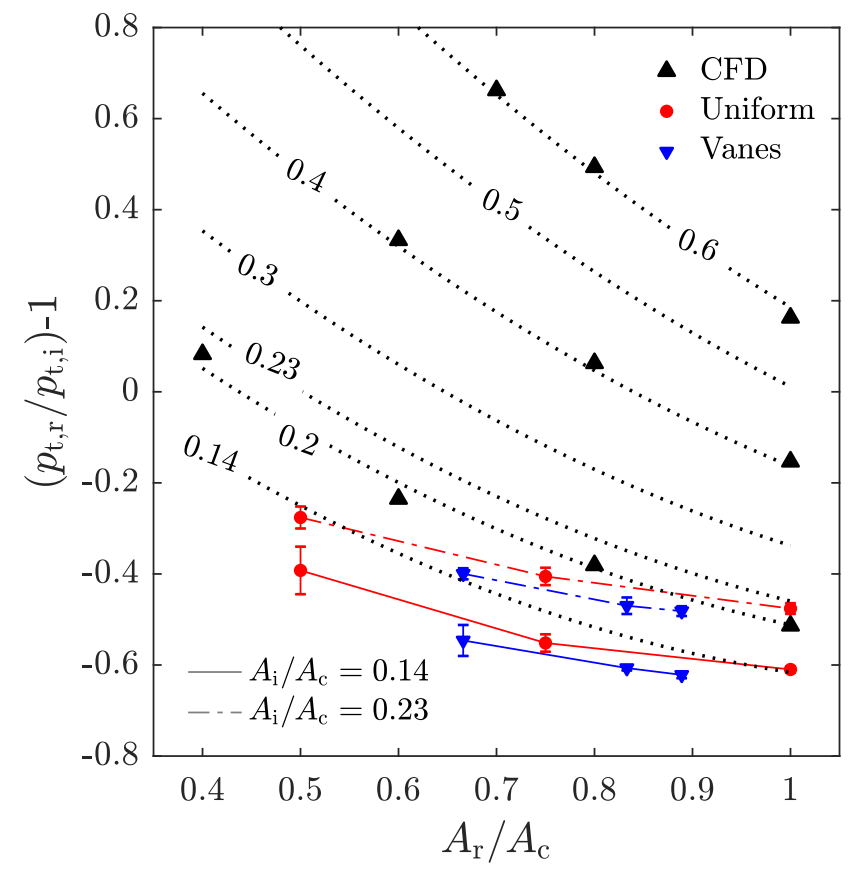

Figure 11: Summary of pressure gain from stagnation pressure measurements for uniform outlet and guide vane configurations. Displayed for comparison are CFD results reproduced from [9]. Vertical bars in the figure represent the spread of pressure gain achieved through mass flux and equivalence ratio variation. 
thrust generation or work extraction. Over a range of injector and outlet area ratios, they perform CFD simulations of the RDC flowfield and calculate the pressure gain of the device in the same way as was presented here. It is therefore worthwhile to compare their findings to the performance of the device used in this study. It should be noted that the referenced CFD simulation is idealized in a number of ways and does not include some effects that are present in real systems (e.g. mixing of reactants, heat transfer to walls, friction losses, operating mode), therefore it is expected to outperform the experimental results obtained in this study. A comparative display of the results is given in Fig. 11, which plots the pressure gain over the throat area ratio. In this figure, black triangles show CFD results for three different injectors with $A_{\mathrm{i}} / A_{\mathrm{c}}=0.2,0.4$, and 0.6 , and throat area ratios ranging from 0.4 to 1.0. This is a much wider range than covered in the present study. Extrapolated from this data were the dotted black lines in Fig. 11, which show expected pressure gain for other $A_{\mathrm{i}} / A_{\mathrm{c}}$ and $A_{\mathrm{r}} / A_{\mathrm{c}}$ combinations. Pairs of red and blue lines display the experimentally obtained results for uniform outlet and guide vane configurations, respectively. The data for these lines were compiled by averaging pressure gain values recorded for mass fluxes above the critical value for the individual configurations (cp. Fig. 10). As the pressure gain may vary substantially, vertical bars illustrate the spread of recorded values due to changes in mass flux, stoichiometry, and operating mode.

The overall positive impacts of increasing $A_{\mathrm{i}} / A_{\mathrm{c}}$ and reducing $A_{\mathrm{r}} / A_{\mathrm{c}}$ on the pressure gain are reflected by the experimental data for both uniform outlet and guide vane setups. For an unobstructed exit, the values are very 
close to the numerical results. At lower throat area ratios, however, the experimental data fall increasingly short of the CFD results (exact numbers are given in the appendix). These results underline that, while no positive pressure gain was recorded in the experiment, this is in line with the performance predicted by CFD and the fact that several loss mechanisms of varying magnitude are present in the experiment. Loss mechanisms include incomplete reactant mixing, mixture stratification, recirculation of burned gas, injector recovery, detonation channel curvature, viscous wall losses, heat transfer to the walls, shock reflections from the outlet, and operating modes vastly different from single wave behavior. The influence of such deviations from the idealized 2-D simulations increase in magnitude as the outlet restriction increases. Additionally, this figure also shows that the spread of possible pressure gain values at one combination of $A_{\mathrm{i}} / A_{\mathrm{c}}$ and $A_{\mathrm{r}} / A_{\mathrm{c}}$ can be large due to changes in operating mode and mass flux. Large deviations from a specific design point could therefore lead to drastic alteration of the RDC's performance. In one extreme case $\left(A_{\mathrm{i}} / A_{\mathrm{c}}=0.14, A_{\mathrm{r}} / A_{\mathrm{c}}=0.5\right)$, the spread was observed to be as large as $\pm 13 \%$.

\section{Conclusions}

This study employed experimentally measured stagnation pressure data to quantify RDC performance over a range of operating and boundary conditions. It was shown that both injector and outlet geometry significantly influence the device's mode of operation, expressed by the propagation velocity of the primary combustion wave and the arrangement of combustion zones within the annulus. Five main modes were described and identified 
and were then used to characterize the combustor's behavior. The establishment of a choking condition was estimated by comparing the stagnation pressure upstream of the throat with that in the surrounding laboratory. Stagnation pressure rise data showed an increasing trend for increasing thermal power, and were influenced by the operational mode only at high mass flux, where transition towards two pairs of counter-rotating waves unlocked further pressure rise. The absence of this self-correcting mechanism resulted in diminishing returns in total pressure rise with increasing mass flux. An analysis of the stagnation-to-static pressure ratio allowed the determination of a bulk flow Mach number inside the combustion chamber, which is in good agreement with a theoretical Mach number based on the throat-to-annulus area ratio. Finally, it was possible to obtain a metric for stagnation pressure gain by comparing the total pressure in the air plenum and upstream of the outlet restriction. This value quantifies the performance of the RDC, including the cost of the associated loss mechanisms, prior to the fluid generating thrust (through a nozzle) or mechanical work (in a turbine). From the combination of the RDC operating map and pressure gain curves, it could be deduced that aside from a low loss injector and high outlet restriction, knowledge of the operating mode is crucial to assessing the actual performance. Adverse modes could be present at the desired operating point and need to be accounted for, as longitudinally pulsing combustion or the inability to transition to multiple co-rotating waves may lead to stagnating or lower than expected pressure gain even when increasing nominal thermal power. This is potentially challenging at part load and off-design operating points, which are regularly encountered in all practical combustion systems. In addition, 
implementing low loss injectors into an RDC while maintaining its operational characteristics is one of today's major hurdles in realizing positive pressure gain. Finally, a comparison of the pressure gain measured in this study with numerically obtained results showed in general similar trends and values, however loss mechanisms in the experiment led to an overprediction in the CFD results for lower throat area ratios.

\section{Acknowledgments}

The investigations presented here were conducted as part of the Luftfahrtforschungsprogramm V-3. The work was supported by the German Federal Ministry for Economic Affairs and Energy as per resolution of the German Bundestag under grant number 20E1712. The responsibility for the content lies solely with its authors.

\section{Appendix}

Section 2.1 described the RDC experiment. As a summary of injector specifications, Table 1 details the two air injectors, and Table 2 details the fuel injector.

\begin{tabular}{ccc}
\hline$g$ in $\mathrm{mm}$ & $A_{\mathrm{i}}$ in $\mathrm{mm}^{2}$ & $A_{\mathrm{i}} / A_{\mathrm{c}}$ \\
\hline 1.0 & 282.7 & 0.1437 \\
1.6 & 452.4 & 0.2299 \\
\hline
\end{tabular}

Table 1: Air injector specifications.

To illustrate the reactant flow rate steadiness as described in Section 2.1, Figure 12 displays data for the plenum pressures and resulting flow rates for 


\begin{tabular}{cccc}
\hline$N_{\mathrm{f}}$ & $d_{\mathrm{f}}$ in $\mathrm{mm}$ & $A_{\mathrm{f}}$ in $\mathrm{mm}^{2}$ & $A_{\mathrm{f}} / A_{\mathrm{c}}$ \\
\hline 100 & 0.5 & 19.6 & 0.0100 \\
\hline
\end{tabular}

Table 2: Fuel injector specifications.

both air and hydrogen at an operating point of $0.4 \mathrm{~kg} \cdot \mathrm{s}^{-1}$, an equivalence ratio $\phi=1.0, A_{\mathrm{i}} / A_{\mathrm{c}}=0.14$, and $A_{\mathrm{r}} / A_{\mathrm{c}}=0.75$. As can be seen, the variation in the data is negligible and the flow rates can be considered constant throughout the run.

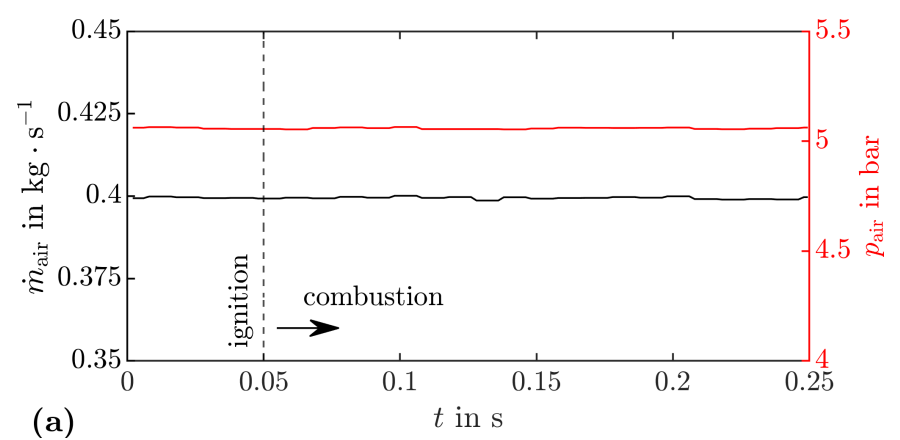

(a)

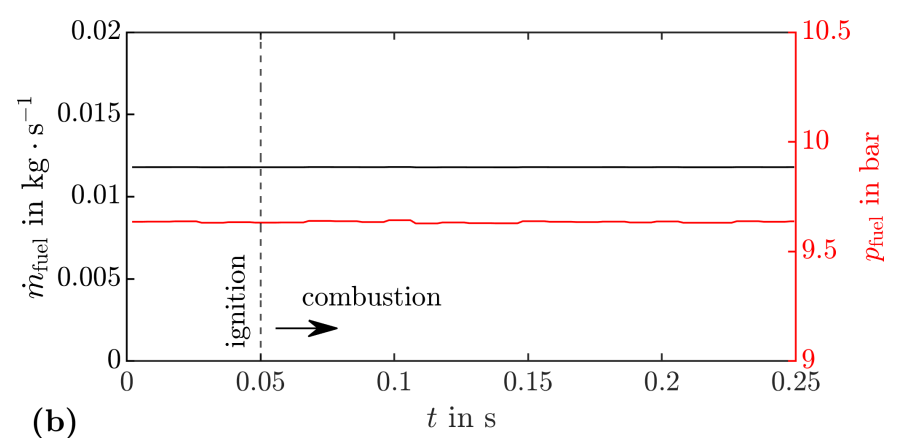

Figure 12: Example plenum pressure and flow rate data for (a) air and (b) hydrogen of one experimental run at nominal values of $\dot{m}_{\text {air }}=0.4 \mathrm{~kg} \cdot \mathrm{s}^{-1}, \phi=1.0, A_{\mathrm{i}} / A_{\mathrm{c}}=0.14$, and $A_{\mathrm{r}} / A_{\mathrm{c}}=0.75$. 
Figure 6 displayed the major observed modes. Table 3 summarizes the classification in terms of the number and velocity of the observed waves according to [50].

\begin{tabular}{c|ccccc}
\hline Mode & $2 \mathrm{CR}$ & $\mathrm{SWCC}$ & $\mathrm{SW}$ & $4 \mathrm{CR}$ & $\mathrm{L}$ \\
\hline$N_{\mathrm{p}}$ & 1 & 1 & 1 & 2 & 1 \\
$N_{\mathrm{s}}$ & 1 & $1-3$ & 0 & $2-3$ & 0 \\
$v_{\mathrm{p}}$ & $\approx c_{\mathrm{det}}$ & $\leq 0.7 v_{\mathrm{CJ}}$ & $>0.7 v_{\mathrm{CJ}}$ & $\approx 0.6 v_{\mathrm{CJ}}$ & $\approx c_{\mathrm{det}}$ \\
$v_{\mathrm{s}}$ & $\approx c_{\mathrm{det}}$ & $\approx c_{\mathrm{det}}$ & - & $\approx 0.6 v_{\mathrm{CJ}}$ & - \\
\hline
\end{tabular}

Table 3: Classification of operating modes according to the number of primary waves $N_{\mathrm{p}}$, the number of secondary counter-rotating waves $N_{\mathrm{s}}$, and the associated wave speeds $v_{\mathrm{p}}$ and $v_{\mathrm{s}}$ in relation to the speed of sound in the combustion products $c_{\mathrm{det}}$ and the CJ velocity $v_{\mathrm{CJ}}$.

Figure 11 gave a comparison of measured stagnation pressure difference across the RDC compared to values interpolated from CFD simulations of an idealized system [9]. Table 4 summarizes the numerical and experimental values as well as the resulting difference. 


\begin{tabular}{llllll}
\hline Config. & $A_{\mathrm{i}} / A_{\mathrm{c}}$ & $A_{\mathrm{r}} / A_{\mathrm{c}}$ & CFD & Exp. & Diff. \\
\hline \multirow{4}{*}{ Uniform } & 0.14 & 1.00 & -0.61 & -0.61 & 0.00 \\
& & 0.75 & -0.47 & -0.55 & -0.08 \\
& & 0.50 & -0.24 & -0.39 & -0.15 \\
\hline \multirow{4}{*}{ Vanes } & \multirow{2}{*}{0.14} & 0.89 & -0.56 & -0.62 & -0.06 \\
& & 0.83 & -0.53 & -0.60 & -0.07 \\
& & & -0.41 & -0.54 & -0.13 \\
\hline \multirow{4}{*}{ Uniform } & 0.23 & 0.75 & -0.28 & -0.41 & -0.13 \\
& & 0.50 & +0.01 & -0.27 & -0.28 \\
\hline \multirow{4}{*}{ Vanes } & 0.23 & 0.83 & -0.35 & -0.47 & -0.12 \\
& & 0.67 & -0.20 & -0.39 & -0.19 \\
\hline
\end{tabular}

Table 4: Summary of pressure gain results and comparison to estimates from CFD data. 


\section{References}

[1] P. Stathopoulos, Comprehensive Thermodynamic Analysis of the Humphrey Cycle for Gas Turbines with Pressure Gain Combustion, Energies $11(12)$.

[2] F. A. Bykovskii, S. A. Zhdan, E. F. Vedernikov, Continuous Spin Detonations, J Propul Power 22 (6) (2006) 1204-1216.

[3] P. Wolański, Application of the Continuous Rotating Detonation to Gas Turbine, Applied Mechanics and Materials 782 (2015) 3-12.

[4] K. Sprouse, E. D. Lynch, J. B. Stout, S. Claflin, A. Darby, Rotating Detonation Combustion for Gas Turbines - Modeling and System Synthesis to Exceed 65\% Efficiency Goal, in: University Turbine Systems Research Annual Meeting, November 2017.

[5] B. A. Rankin, M. L. Fotia, A. G. Naples, C. A. Stevens, J. L. Hoke, T. A. Kaemming, S. W. Theuerkauf, F. R. Schauer, Overview of Performance, Application, and Analysis of Rotating Detonation Engine Technologies, J Propul Power 33 (1) (2017) 131-143.

[6] A. K. Hayashi, X. Tang, N. Tsuboi, K. Ozawa, K. Ishii, T. Obara, S. Maeda, E. Dzieminska, T. Mizukaki, Development of a High Efficiency System with a Rotating Detonation Engine for a Gas Turbine Engine (RDE-GTE) using Pressure Gain Combustion, AIAA Paper 2019-1509, January 2019. 
[7] J. Braun, B. H. Saracoglu, G. Paniagua, Unsteady Performance of Rotating Detonation Engines with Different Exhaust Nozzles, J Propul Power 33 (1) (2017) 121-130.

[8] Z. Liu, J. Braun, G. Paniagua, Characterization of a Supersonic Turbine Downstream of a Rotating Detonation Combustor, J Eng Gas Turb Power $141(3)$.

[9] T. A. Kaemming, D. E. Paxson, Determining the Pressure Gain of Pressure Gain Combustion, AIAA Paper 2018-4567, July 2018.

[10] J. Sousa, G. Paniagua, E. Collado-Morata, Thermodynamic analysis of a gas turbine engine with a rotating detonation combustor, Appl Energ 195 (2017) 247-256.

[11] D. E. Paxson, T. A. Kaemming, Foundational Performance Analyses of Pressure Gain Combustion Thermodynamic Benefits for Gas Turbines, AIAA Paper 2012-0770, January 2012.

[12] D. E. Paxson, T. A. Kaemming, Influence of Unsteadiness on the Analysis of Pressure Gain Combustion Devices, J Propul Power 30 (2) (2014) $377-383$.

[13] D. E. Paxson, Impact of an Exhaust Throat on Semi-Idealized Rotating Detonation Engine Performance, AIAA Paper 2016-1647, January 2016.

[14] V. Anand, E. J. Gutmark, Rotating detonation combustors and their similarities to rocket instabilities, Prog Energ Combust 73 (2019) 182234. 
[15] G. V. R. Rao, Recent Developments in Rocket Nozzle Configurations, ARS Journal 31 (11) (1961) 1488-1494.

[16] M. L. Fotia, T. A. Kaemming, J. L. Hoke, F. R. Schauer, Study of the Experimental Performance of a Rotating Detonation Engine with Nozzled Exhaust Flow, AIAA Paper 2015-0631, January 2015.

[17] M. L. Fotia, T. A. Kaemming, J. R. Codoni, J. L. Hoke, F. R. Schauer, Experimental Thrust Sensitivity of a Rotating Detonation Engine to Various Aerospike Plug-Nozzle Configurations, AIAA Paper 2019-1743, January 2019.

[18] D. E. Paxson, M. L. Fotia, J. L. Hoke, F. R. Schauer, Comparison of Numerically Simulated and Experimentally Measured Performance of a Rotating Detonation Engine, AIAA Paper 2015-1101, January 2015.

[19] B. A. Rankin, J. L. Hoke, F. R. Schauer, Periodic Exhaust Flow through a Converging-Diverging Nozzle Downstream of a Rotating Detonation Engine, AIAA Paper 2014-1015, January 2014.

[20] D. P. Stechmann, Experimental Study of High-Pressure Rotating Detonation Combustion in Rocket Environments, Phd thesis, Purdue University (2017).

[21] D. P. Stechmann, S. D. Heister, A. J. Harroun, Rotating Detonation Engine Performance Model for Rocket Applications, J Spacecraft Rockets 56 (3) (2019) 887-898.

[22] S. M. Frolov, V. S. Aksenov, V. S. Ivanov, I. O. Shamshin, Large-scale 
hydrogen-air continuous detonation combustor, Int J Hydrogen Energ 40 (3) (2015) 1616-1623.

[23] J. Nishimura, K. Ishihara, K. Goto, S. Nakagami, K. Matsuoka, J. Kasahara, A. Matsuo, I. Funaki, H. Mukae, K. Yasuda, D. Nakata, K. Higashino, H. Moriai, Performance Evaluation of a Rotating Detonation Engine for Space Use, in: Proceedings of the 26th ICDERS, 2017.

[24] K. Goto, R. Yokoo, J. Kim, A. Kawasaki, K. Matsuoka, J. Kasahara, A. Matsuo, I. Funaki, D. Nakata, M. Uchiumi, K. Higashino, Experimental Performance Validation of a Rotating Detonation Engine toward a Flight Demonstration, AIAA Paper 2019-1501, January 2019.

[25] J. R. Tellefsen, Build Up and Operation of an Axial Turbine Driven by a Rotary Detonation Engine, Master thesis, Air Force Institute of Technology (2012).

[26] N. D. DeBarmore, Characterization of Rotating Detonation Engine Exhaust Through Nozzle Guide Vanes, Master thesis, Air Force Institute of Technology (2013).

[27] A. G. Naples, M. L. Fotia, S. W. Theuerkauf, J. L. Hoke, F. R. Schauer, Design and Testing of a Rotating Detonation Engine for Open-Loop Gas Turbine Integration, in: Proceedings of the 25th ICDERS, 2015.

[28] A. G. Naples, J. L. Hoke, R. T. Battelle, F. R. Schauer, T63 Turbine Response To Rotating Detonation Combustor Exhaust Flow, J Eng Gas Turb Power 141 (2) (2019) 1-11. 
[29] P. Kalina, P. Wolański, W. Balicki, W. Perkowski, A. Rowiński, A. Kobiera, J. Kindracki, Report on the Implementation of the POIG Project "Turbine Engine with a Detonation Combustion Chamber", Journal of KONES 23 (2) (2016) 177-184.

[30] J. Higashi, S. Nakagami, K. Matsuoka, J. Kasahara, A. Matsuo, I. Funaki, H. Moriai, Experimental Study of the Disk-Shaped Rotating Detonation Turbine Engine, AIAA Paper 2017-1286, January 2017.

[31] H. Rhee, C. Ishiyama, J. Higashi, Experimental Study on a Rotating Detonation Turbine Engine with an Axial Turbine, in: Proceedings of the 26th ICDERS, 2017.

[32] R. Huff, M. D. Polanka, M. J. McClearn, F. R. Schauer, M. L. Fotia, J. L. Hoke, A Disk Rotating Detonation Engine Driven Auxiliary Power Unit, AIAA Paper 2018-4879, July 2018.

[33] R. Huff, F. R. Schauer, S. A. Boller, M. D. Polanka, M. L. Fotia, J. L. Hoke, Exit Condition Measurements of a Radial Rotating Detonation Engine Bleed Air Turbine, AIAA Paper 2019-1011, 2019.

[34] S. Zhou, H. Ma, S. Li, D. Liu, Y. Yan, C. Zhou, Effects of a turbine guide vane on hydrogen-air rotating detonation wave propagation characteristics, Int J Hydrogen Energ 42 (31) (2017) 20297-20305.

[35] S. Zhou, H. Ma, Y. Yang, C. Zhou, Investigation on propagation characteristics of rotating detonation wave in a radial-flow turbine engine combustor model, Acta Astronaut 160 (2019) 15-24. 
[36] G. Paniagua, M. C. Iorio, N. Vinha, J. Sousa, Design and analysis of pioneering high supersonic axial turbines, Int J Mech Sci 89 (2014) 6577.

[37] C. Sonwane, E. D. Lynch, S. Claflin, J. B. Stout, Recent Advances in Power Cycles Using Rotating Detonation Engines with Subcritical and Supercritical CO2, in: 4th Internation Symposium - Supercritical CO2 Power Cycles, September 2014.

[38] E. D. Lynch, J. B. Stout, S. Claflin, Rotating Detonation Combustion for Gas Turbines - Modeling and System Synthesis to Exceed 65\% Efficiency Goal, in: University Turbine Systems Research Workshop, November 2015.

[39] M. D. Bohon, R. Bluemner, C. O. Paschereit, E. J. Gutmark, Highspeed imaging of wave modes in an RDC, Exp Therm Fluid Sci 102 (2019) 28-37.

[40] R. Bluemner, M. D. Bohon, C. O. Paschereit, E. J. Gutmark, Experimental Study of Reactant Mixing in Model Rotating Detonation Combustor Geometries, Flow Turbul Combust 102 (2) (2019) 255-277.

[41] E. N. Jacobs, K. E. Ward, R. M. Pinkerton, The Characteristics of 78 Related Airfoil Sections from Tests in the Variable-Density Wind Tunnel, Tech. rep., National Advisory Committee for Aeronautics, Washington, DC (1933).

[42] M. L. Fotia, J. L. Hoke, F. R. Schauer, Experimental Study of the 
Response of Capillary Tube Attenuated Pressure Measurements to High Amplitude, Non-Linear Forcing, AIAA Paper 2018-0634, January 2018.

[43] G. Kiel, Total-Head Meter with Small Sensitivity to Yaw, Luftfahrtforschung 12 (2) (1935) 75-79.

[44] S. H. Chue, Pressure Probes for Fluid Measurement, Prog Aerosp Sci 16 (2) (1975) 147-223.

[45] D. Depperschmidt, J. Tobias, R. Miller, A. K. Agrawal, Time-Resolved PIV Measurements of Flow Field at the Exit of a Diffuser Mounted on a Rotating Detonation Combustor, AIAA Paper 2019-4379, August 2019.

[46] D. A. Schwer, C. M. Brophy, R. H. Kelso, Pressure Characteristics of an Aerospike Nozzle in a Rotating Detonation Engine, AIAA Paper 20184968, July 2018.

[47] E. Bach, M. D. Bohon, C. O. Paschereit, P. Stathopoulos, Development of an Instrumented Guide Vane Set for RDC Exhaust Flow Characterization, AIAA Paper 2018-4479, July 2018.

[48] S. Yahya, Fundamentals of Compressible Flow: With Aircraft and Rocket Propulsion, New Age Science, 2010.

[49] B. J. McBride, S. Gordon, Computer Program for Calculation of Complex Chemical Equilibrium Compositions and Applications, Tech. rep., NASA (1996).

[50] R. Bluemner, M. D. Bohon, C. O. Paschereit, E. J. Gutmark, Counter- 
rotating wave mode transition dynamics in an RDC, Int J Hydrogen Energ 44 (14) (2019) 7628-7641.

[51] J. Kindracki, P. Wolański, Z. Gut, Experimental research on the rotating detonation in gaseous fuels-oxygen mixtures, Shock Waves 21 (2) (2011) $75-84$.

[52] A. C. St. George, R. B. Driscoll, D. E. Munday, E. J. Gutmark, Development of a Rotating Detonation Engine Facility at the University of Cincinnati, AIAA Paper 2015-0635, January 2015.

[53] A. C. St. George, R. B. Driscoll, V. Anand, E. J. Gutmark, On the existence and multiplicity of rotating detonations, P Combust Inst 36 (2) (2017) 2691-2698.

[54] V. Anand, A. C. St. George, R. B. Driscoll, E. J. Gutmark, Longitudinal pulsed detonation instability in a rotating detonation combustor, Exp Therm Fluid Sci 77 (2016) 212-225.

[55] S. M. Frolov, V. I. Zvegintsev, V. S. Ivanov, I. O. Shamshin, V. M. Fomin, A. A. Berlin, V. S. Aksenov, D. A. Vnuchkov, D. G. Nalivaichenko, Continuous Detonation Combustion of Hydrogen: Results of Wind Tunnel Experiments, Combust Explo Shock+ 54 (3) (2018) $357-363$. 